2017-02

\title{
Sidewall Buckling of Equal-Width RHS Truss X-Joints
}

\section{Becque, J}

http://hdl.handle.net/10026.1/10518

10.1061/(ASCE)ST.1943-541X.0001677

Journal of Structural Engineering

American Society of Civil Engineers (ASCE)

All content in PEARL is protected by copyright law. Author manuscripts are made available in accordance with publisher policies. Please cite only the published version using the details provided on the item record or document. In the absence of an open licence (e.g. Creative Commons), permissions for further reuse of content should be sought from the publisher or author. 


\section{Sidewall Buckling of Equal-width RHS Truss X- Joints}

Article in Journal of Structural Engineering · September 2016

DOI: 10.1061/(ASCE)ST.1943-541X.0001677

\section{CITATIONS}

0

2 authors, including:

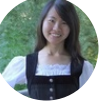

Shanshan Cheng

The University of Sheffield

14 PUBLICATIONS 17 CITATIONS

SEE PROFILE
READS

17

All content following this page was uploaded by Shanshan Cheng on 14 October 2016.

The user has requested enhancement of the downloaded file. All in-text references underlined in blue are added to the original document and are linked to publications on ResearchGate, letting you access and read them immediately. 
Abstract: This paper presents a new design methodology for equal-width rectangular hollow section (RHS) X-joints failing by sidewall buckling. In the new approach, a slenderness parameter is defined based on the elastic local buckling stress of the sidewall, idealized as an infinitely long plate under patch loading. A Rayleigh-Ritz approximation is thereby used to obtain a closed-form solution. The proposed design equation is verified against experimental results over a wide range of wall slenderness values obtained from the literature and complemented by a brief experimental program carried out by the authors. It is demonstrated that the new design equation yields excellent results against the experimental data. Finally, a reliability analysis is performed within the framework of both the Eurocode and the AISI standards to ensure that the proposed design equation possesses the required level of safety. The newly proposed equation strongly outperforms the current Comité International pour le Développement et l'Etude de la Construction Tubulaire (CIDECT) design rule for sidewall buckling and also further extends the range of applicability to a wall slenderness ratio of up to 50. DOI: 10.1061/(ASCE)ST .1943-541X.0001677. (C) 2016 American Society of Civil Engineers.

Author keywords: Hollow sections; Connections; Joints; Sidewall buckling; Rectangular hollow section (RHS); SHS; Design; Metal and composite structures.

\section{Introduction}

Steel hollow sections are widely used in engineering structures. Historically, circular hollow sections (CHS) were the first hollow sections to be used in structural applications and were valued by engineers because of their favorable properties such as high structural efficiency in compression and bending, high strength and stiffness in torsion, aesthetic appeal, reduced exposed area, and reduced drag coefficient in fluid flow (Wardenier et al. 2010). However, the difficulties associated with establishing CHS connections (in particular, the need to profile-cut the ends of the members) initially hampered their wider application. While modern computer-aided manufacturing techniques have alleviated much of this problem, this technology is not always available to smaller manufacturers or in less developed areas of the world. Therefore, rectangular hollow sections (RHS) are often preferred in practice, owing to the fact that the use of RHS significantly simplifies the connections by enabling straight end cuts while maintaining nearly the same favorable structural properties as CHS.

Truss structures form an important application of RHS members and welded RHS trusses are often found in large roof spans, pedestrian bridges, walkways, and offshore structures. In the design of these trusses, the joints require particular attention as they are susceptible to a number of particular failure modes. Research on welded hollow section joints has been carried out for many decades, and Comité International pour le Développement et l'Etude de la Construction Tubulaire (CIDECT) has been very instrumental in this, while also issuing regularly upgraded versions of the design

${ }^{1}$ Lecturer, Dept. of Civil and Structural Engineering, Univ. of Sheffield, Sheffield, U.K. E-mail: j.becque@sheffield.ac.uk

${ }^{2}$ Postdoctoral Research Associate, Dept. of Civil and Structural Engineering, Univ. of Sheffield, Sheffield, U.K. (corresponding author). E-mail: shanshan.cheng@sheffield.ac.uk

Note. This manuscript was submitted on February 2, 2016; approved on August 4, 2016№ Epub Date. Discussion period open until 0, 0; separate discussions must be submitted for individual papers. This paper is part of the Journal of Structural Engineering, (C) ASCE, ISSN 0733-9445. rules for hollow section joints. The most recent version of the design rules can be found in (Packer et al. 2009).

This paper focuses on right-angle $\mathrm{X}$-joints between equal-width RHS truss members (Fig. 1). For these types of joints, sidewall buckling of the chord member is the critical failure mode in compression.

In the current CIDECT design rules, sidewall buckling is accounted for by isolating a vertical strip in the chord sidewall and designing it as a column (Packer 1984). While defendable because of its simplicity, this approach obviously ignores the twodimensional character of the sidewall buckling as a plate. Moreover, it has been known for some time that the current CIDECT design rules for chord sidewall failure are quite conservative, and more so as the chord wall slenderness $h_{0} / t_{0}$ increases (Becque and Wilkinson 2011). This paper follows the established CIDECT nomenclature, where $h_{0}$ and $h_{1}$ are the chord height and the brace height, respectively; $b_{0}$ and $b_{1}$ represent the chord width and the brace width, respectively; and $t_{0}$ and $t_{1}$ refer to the thicknesses of the chord wall and the brace wall, respectively (Fig. 2).

The aim of this paper is to present an alternative design equation for chord sidewall buckling, equally simple in its application, but founded on a rational plate buckling model and verified against experimental data.

In previous research, Brodka and Szlendak (1980) carried out over 400 tests on RHS X-joints. However, these RHS were fabricated by welding two cold-formed channel sections together at the toes. A semiempirical equation was developed for the ultimate strength of the $\mathrm{X}$-joints as a function of the ratio of the brace width to the chord width. Since this particular manufacturing technique is rather different from the way RHS are currently produced, no further consideration was given to the experimental data in this paper. Brodka and Szlendak (1980) also presented an equation based on the chord slenderness $\left(h_{0} / t_{0}\right)$, which formed a lower bound to the experimental results. Wardenier $(1980,1982)$ carried out further experimental studies on RHS T- and X-joints, with the brace members loaded either in tension or compression. Both hot-finished and cold-finished hollow sections with nominal yield stresses of 240 and $275 \mathrm{MPa}$ were used. It was observed that for equal-width $\mathrm{X}$-joints, the strength of the joint in compression is 


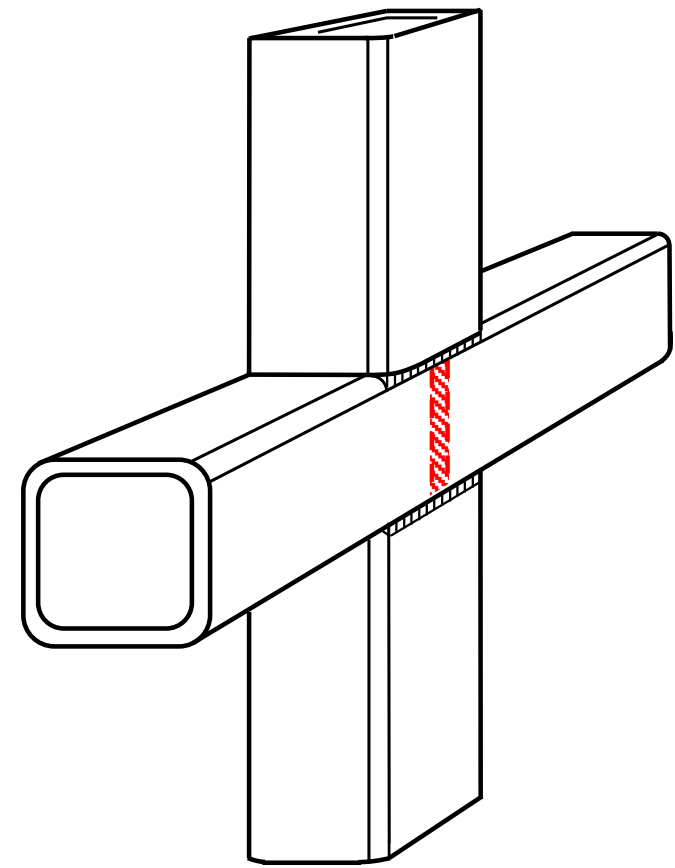

Fig. 1. CIDECT design model
A total of 31 tests on equal-width X-joints, with either RHS brace members or simple plates welded to the RHS chord members, were carried out by Packer (1984). Both hot-formed and coldformed RHS tubes were considered, with chord depths $h_{0}$ ranging from 77.6 to $304.4 \mathrm{~mm}$, and wall slenderness values $\left(h_{0} / t_{0}\right)$ ranging from 15.3 to 42.2 . The effects of the brace member angle $\theta$ (Fig. 2) and the presence of a compressive chord preload were investigated. A unified equation to calculate the ultimate strength in sidewall failure of both $\mathrm{T}$ - and $\mathrm{X}$-joints was provided. However, neither the chord depth $\left(h_{0}\right)$ nor the axial chord preload was included in the equation, as they were believed to have little effect on the ultimate strength of the joints. At a later stage, the former conclusion was refuted by Davies and Packer (1987), who instead postulated that the joint strength depends on the chord slenderness $\left(h_{0} / t_{0}\right)$ and the nondimensional bearing length $\left(h_{1} / h_{0}\right)$.

Zhang et al. (1990), Shen and Zhang (1990), and Fang (2004) also carried out experimental and numerical studies on the strength of RHS X-joints using RHS commercially available in China, including a number of equal-width joints. Shen and Zhang (1990) proposed a simplified design equation based on a rudimentary plastic collapse mechanism to predict the ultimate strength of equal-width X-joints. However, guided by the research in (Packer 1984), the effects of the chord depth $\left(h_{0}\right)$ and the axial compressive chord preload were again excluded.

\section{Design Philosophy}

The design process of an RHS truss typically starts with a structural analysis under various load combinations in order to determine the governing internal forces. These internal forces consist mainly of tensile or compressive forces, accompanied by secondary moments sidewalls. A unified equation for both failure modes was provided, in which the buckling stress was derived based on the model of a pin-ended strut with an effective length of $\left(h_{0}-2 t_{0}\right)$. This research formed the basis of the current CIDECT design rule.
112

113

114
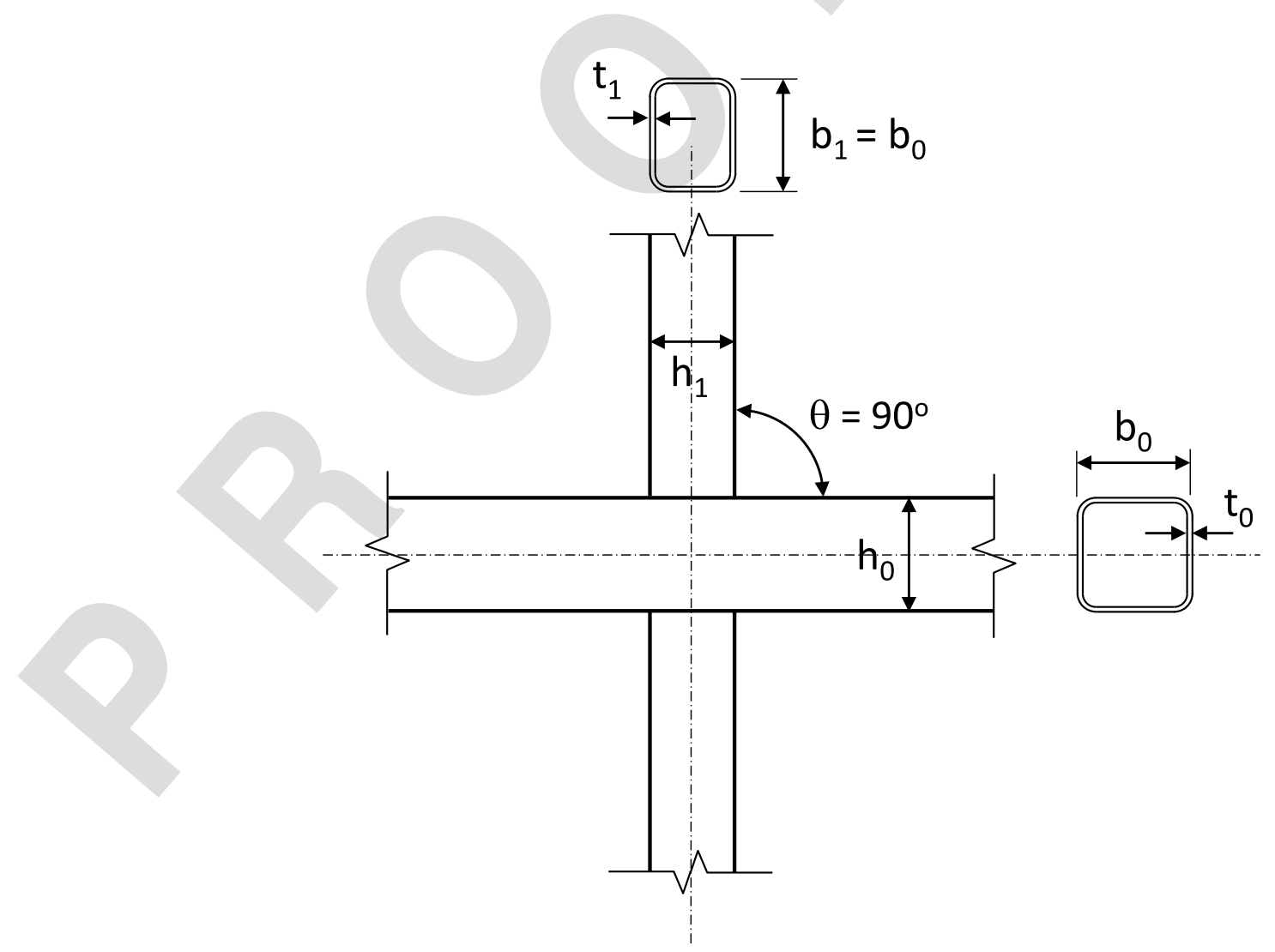

Fig. 2. Connection geometry 


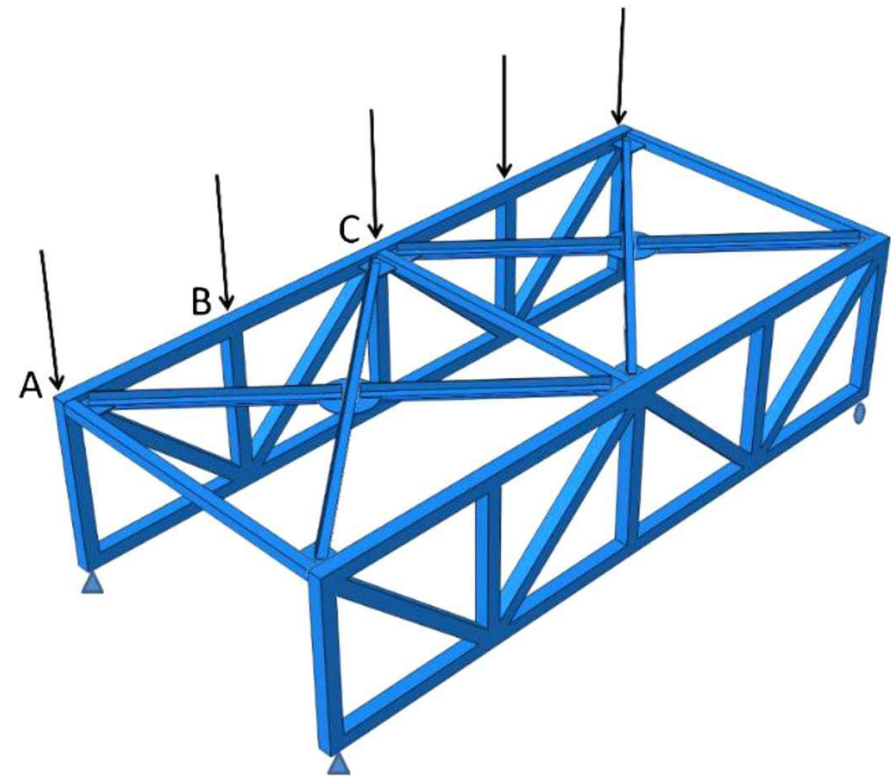

Fig. 3. Sample RHS truss
116

117

118

119

120 which can typically be considered negligible as long as the joint eccentricities are within the CIDECT prescribed values (Packer et al. 2009) and the brace members are sufficiently slender. The actual design procedure then follows two steps:

1. sizing of the brace and chord members of the truss as tension or compression members; and

2. a separate check of the connection capacities accounting for all possible failure modes using the CIDECT rules.

The design of compressive truss members under (1) requires the determination of an effective length. As an example, we consider the truss in Fig. 3 under the loading shown, with particular focus on the top chord. Given the arrangement of the top bracing, the top chord needs to be designed as a column spanning between points $\mathrm{A}$ and $\mathrm{C}$ with out-of-plane flexural buckling being the governing beneficial restraint exerted by the brace member at B for design purposes). The implicit assumption in carrying out this check, however, is that the $\mathrm{X}$-joint at B remains sound. Indeed, if local buckling were to occur in the chord sidewall at B, this would introduce a weak link in the column A-C, which would greatly reduce its out-of-plane flexural buckling capacity. It is well known that when local buckling occurs, the loss in compressive stiffness of a plate is immediate and severe [e.g., (Marguerre 1937); (Hemp 1945)]. The system could then be likened to a Shanley column failure mode (the common practice is thereby to neglect the
(Shanley 1947), albeit one where localized geometric nonlinearity rather than localized material nonlinearity (or possibly a combination of both) would be the cause of the central weak link. However, the design philosophy outlined in the two steps above has no way of accounting for this type of local-global interactive buckling, since the checks for flexural buckling of the member and local buckling of the connection are carried out independently and both modes are assumed to be uncoupled. The most straightforward solution to this problem (and the one adhered to in this paper) is to limit the design capacity of an X-joint to its sidewall buckling load (which may be elastic or inelastic) and neglect any postbuckling capacity, thereby eliminating the potential for nonlinear mode interaction altogether. This philosophy is, in a sense, consistent with the current CIDECT rule for sidewall failure based on flexural buckling of a column strip. However, it does not condone the widespread practice of determining the capacity of an X-joint as the minimum of either the peak load or the load corresponding to the $0.03 b_{0}$ deformation limit (Lu et al. 1994) from a test on an isolated connection. Any argument that buckling of the sidewall will lead to a rapid increase in sidewall deformations and that, therefore, the load corresponding to a deformation of $0.03 b_{0}$ will be representative of the buckling load is quickly invalidated by experimental evidence. Out of the five tests X1-X5 conducted at the University of Sheffield and described in the next section, four of them reached the full peak load before even reaching the $0.03 b_{0}$ sidewall deformation and in no case was the $0.03 b_{0}$ limit load representative of the buckling load.

\section{Experimental Program}

Although an abundance of experimental results on equal-width RHS X-joints is available in the literature, the recorded data typically include the peak load and (in most cases) the load corresponding to the $3 \% b_{0}$ deformation limit (Fang 2004; Packer 1984; Wardenier 1980, 1982), while the load at which buckling of the sidewall is first observed routinely remains unreported. A limited experimental program was therefore conceived at the University of Sheffield encompassing five tests on equal-width $90^{\circ} \mathrm{X}$-joints with varying chord wall slenderness $h_{0} / t_{0}$.

\section{Test Specimen Properties}

All specimens (labeled X1-X5) were made of hot-finished $100 \times 100$ SHS, while the wall thicknesses of the chord and the brace members were varied from 3 to $8 \mathrm{~mm}$. The measured cross-sectional dimensions of all specimens are reported in Table 1 and the overall dimensions of a typical test specimen are shown in Fig. 4.
Table 1. Measured Dimensions
176

177

\begin{tabular}{|c|c|c|c|c|c|c|c|c|c|c|c|c|c|c|}
\hline Labe & Nominal chord size & Nominal brace size & $\begin{array}{c}h_{0} \\
(\mathrm{~mm}) \\
\end{array}$ & $\begin{array}{c}b_{0} \\
(\mathrm{~mm}) \\
\end{array}$ & $\begin{array}{c}t_{0} \\
(\mathrm{~mm})\end{array}$ & $\begin{array}{c}r_{0}^{(1)} \\
(\mathrm{mm}) \\
\end{array}$ & $\begin{array}{c}b_{1} \\
(\mathrm{~mm}) \\
\end{array}$ & $\begin{array}{c}h_{1} \\
(\mathrm{~mm}) \\
\end{array}$ & $\begin{array}{c}t_{1} \\
(\mathrm{~mm}) \\
\end{array}$ & $\begin{array}{c}r_{1}^{a} \\
(\mathrm{~mm}) \\
\end{array}$ & $\begin{array}{c}\Delta \text { (left) } \\
(\mathrm{mm})\end{array}$ & $\begin{array}{c}\Delta \text { (right) } \\
(\mathrm{mm})\end{array}$ & $\begin{array}{c}f_{y} \\
(\mathrm{MPa}) \\
\end{array}$ & $\begin{array}{c}f_{u} \\
(\mathrm{MPa}) \\
\end{array}$ \\
\hline $\mathrm{X} 1$ & $100 \times \times 100 \times \times 3$ & $100 \times \times 100 \times \times 3$ & 100.27 & 100.52 & 2.92 & 6.20 & 100.22 & 100.33 & 2.73 & 6.20 & -0.05 & -0.05 & 330 & 388 \\
\hline $\mathrm{X} 2$ & $100 \times \times 100 \times \times 4$ & $100 \times \times 100 \times \times 4$ & 100.14 & 100.36 & 3.84 & 11.5 & 100.37 & 100.19 & 3.69 & 11.5 & -0.05 & -0.30 & 330 & 404 \\
\hline $\mathrm{X} 3$ & $100 \times \times 100 \times \times 5$ & $100 \times \times 100 \times \times 5$ & 99.80 & 100.25 & 4.89 & 12.7 & 100.08 & 99.90 & 4.70 & 12.7 & -0.20 & -0.10 & 400 & 437 \\
\hline $\mathrm{X} 4$ & $100 \times \times 100 \times \times 6$ & $100 \times \times 100 \times \times 6$ & 99.61 & 99.63 & 5.80 & 12.1 & 99.76 & 99.66 & 5.46 & 12.1 & -0.05 & -0.20 & 370 & 425 \\
\hline X5 & $100 \times \times 100 \times \times 8$ & $100 \times \times 100 \times \times 8$ & 99.70 & 99.89 & 7.92 & 15.1 & 100.12 & 99.64 & 7.68 & 15.1 & -0.15 & -0.15 & 345 & 392 \\
\hline X6 & $250 \times \times 150 \times \times 5$ & $50 \times \times 5$ & 250.00 & 149.77 & 5.00 & 17.7 & 150.10 & 150.10 & 4.76 & 11.4 & 3.0 & 2.0 & 463 & 513 \\
\hline X7 & $150 \times \times 150 \times \times 6$ & $150 \times \times 150 \times \times 6$ & 150.18 & 150.23 & 5.86 & 14.1 & 150.48 & 150.35 & 5.86 & 14.7 & -1.0 & -1.0 & 451 & 502 \\
\hline X8 & $350 \times \times 250 \times \times 10$ & $250 \times \times 250 \times \times 10$ & 350.40 & 250.70 & 9.94 & 27.0 & 248.50 & 249.00 & 9.94 & 26.6 & 0.0 & 0.0 & 468 & 534 \\
\hline X9 & $400 \times \times 300 \times \times 8$ & $300 \times \times 300 \times \times 8$ & 400.00 & 300.00 & 7.92 & 22.7 & 300.30 & 300.30 & 7.97 & 22.3 & 2.0 & 2.0 & 481 & 546 \\
\hline
\end{tabular}

$r=$ outside corner radius. 


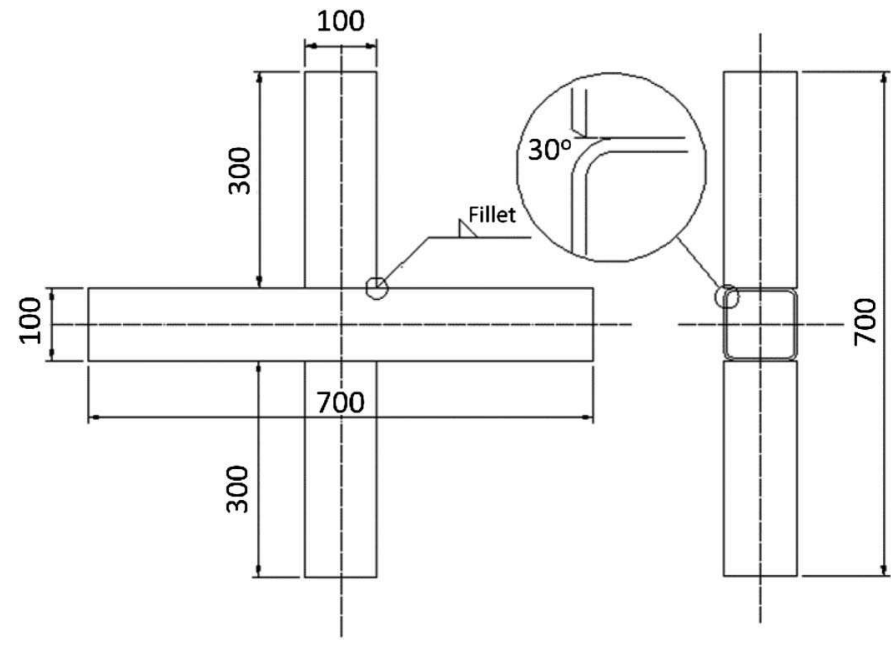

Fig. 4. Specimen dimensions and weld configuration
A 20 s welding procedure was used with W46_2_3Si1 wire $\left(f_{y}=460 \mathrm{MPa}, f_{u}=600 \mathrm{MPa}\right)$. A simple 5-mm (X1), 8-mm (X2-X4), or 10-mm (X5) fillet weld was used to connect the top and bottom faces of the chord to the brace members, while the sidewalls were connected to the brace members using a butt weld with a $30^{\circ}$ bevel on the brace ends (Fig. 4).

The material grade was S355H [to EN10210-1: 2006 (CEN 2006)] for all SHS. Tensile coupons were cut from leftover pieces of the SHS segments used to fabricate the chord members and one coupon specimen was taken from each chord size. All coupons were tested using a displacement rate of $2 \mathrm{~mm} / \mathrm{min}$, which approximately corresponded to a strain rate of $5.85 \times 10^{-4} \mathrm{~s}^{-1}$. The tests were repeatedly paused for 2 min to allow the load to settle and to eliminate strain rate-dependent effects. All coupons were instrumented with an extensometer with a 50-mm base and two 5-mm strain gauges on both sides of the coupon at midheight to allow for a more accurate determination of the initial elastic modulus.

The yield stress $f_{y}$ (defined as the $0.2 \%$ proof stress) and the tensile strength $f_{u}$ obtained for each chord size are listed in Table 1. The average $0.2 \%$ proof stress was found to be $f_{y}=355 \mathrm{MPa}$, while the average tensile strength was $f_{u}=409 \mathrm{MPa}$. The reported values are lower-bound static stresses, obtained by pausing the test for 2 min at three strain levels $(0.5,5$, and $10 \%)$ and allowing the load to settle in order to eliminate strain rate-dependent effects.

The imperfection of the chord sidewall at the connection with the brace members (i.e., the bulge $\Delta$ of the sidewall relative to the corners) was measured with a feeler gauge and is also reported in Table 1. A negative value indicates an imperfection toward the inside of the tube.

\section{Test Setup}

A $2,000-\mathrm{kN}$ test machine was used to apply a compressive load to the connection between fixed end conditions. A uniform introduction of the load into the brace members was ensured by the presence of a plate mounted on a spherical hinge underneath the ram, which made an even contact with the specimen before locking into place when the load was applied. All specimens were instrumented with two linear voltage differential transducers (LVDTs) positioned on the underside of the above-mentioned plate to measure the axial shortening of the specimen, and another two LVDTs were placed at the centers of the chord sidewalls on either side of the connection to measure the sidewall displacements (Fig. 5).

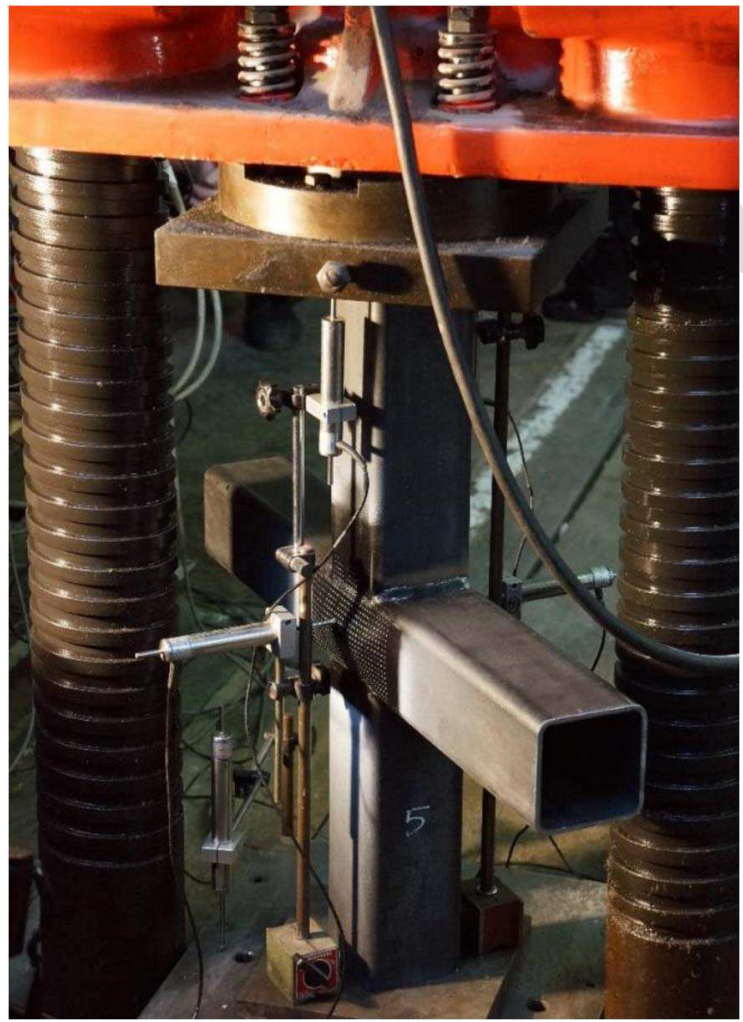

Fig. 5. Test setup

\section{Test Results}

Sidewall buckling was observed in all specimens X1-X5 (Fig. 6). Fig. 7(a) shows the load versus axial shortening diagrams of all specimens, while Fig. 7(b) shows the sidewall displacements as a function of the load. The test results are summarized in Table 2 , which lists the ultimate load $P_{\text {ult }}$, as well as the sidewall buckling load $P_{b, \text { test }}$.

The more slender $\mathrm{X}$-joints (X1 and $\mathrm{X} 2$ ) displayed buckling in the elastic range. In this case, the buckling load could accurately be determined from the sudden change in axial stiffness of the specimens and the simultaneous increase in sidewall deflections [Figs. 8(a and b)]. In Fig. 8, the red line indicates the initial (elastic) stiffness of the connection, while the orange dashed line indicates the buckling load, determined on the basis of the change in slope in Fig. 8(a). However, the more stocky joints (X4 and X5) buckled in the inelastic range, where buckling was interwoven with the loss of stiffness resulting from gradual material yielding, making the onset of buckling more difficult to pinpoint (Fig. 9). For these joints, a sudden increase in sidewall deflections [Fig. 9(b)] provided the only indication of buckling. The help of finite-element simulations, described in the next section, was enlisted to more accurately determine the buckling load.

\section{Weld Investigation}

A macro etch test was carried out to investigate the weld penetration at the junction between the chord sidewall and the brace members. All five test specimens X1-X5 were cut in half along the vertical plane of symmetry through the sidewall. In order to achieve the necessary finish, the weld areas in the cross section were polished in four steps using progressively finer grit sizes: a 120-grit sand disc as the primary polishing tool, followed by coarse, medium, and very fine aluminum oxide discs. The weld 


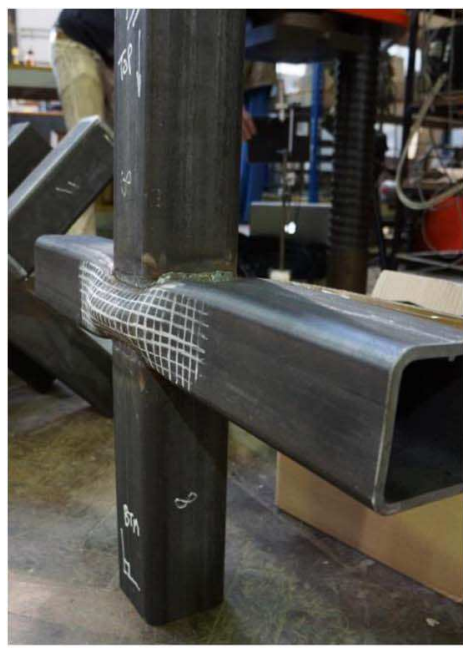

(a)

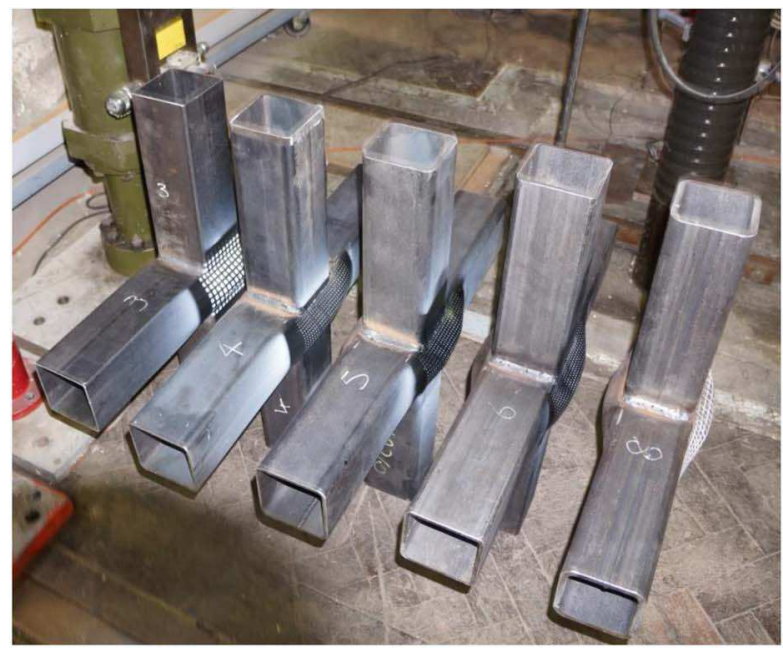

(b)

Fig. 6. Failed specimens: (a) X5; (b) X1-X5
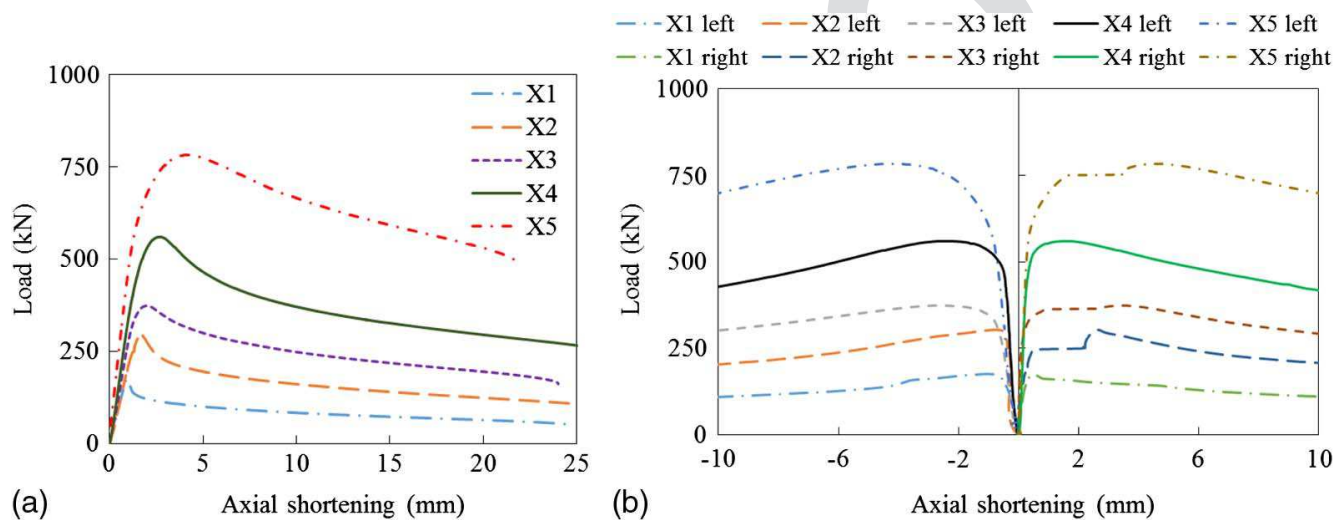

Fig. 7. Load-displacement relationship of all tests: (a) load versus axial shortening; (b) load versus lateral shortening

Table 2. Test Results

\begin{tabular}{lccccr}
\hline Test & Nominal chord size & Nominal brace size & $h_{0} / t_{0}$ & $\begin{array}{c}P_{\text {ult }} \\
(\mathrm{kN})\end{array}$ & $\begin{array}{c}P_{b, \text { test }} \\
(\mathrm{kN})\end{array}$ \\
\hline X1 & $100 \times \times 100 \times \times 3$ & $100 \times \times 100 \times \times 3$ & 34.3 & 176 & 124 \\
X2 & $100 \times \times 100 \times \times 4$ & $100 \times \times 100 \times \times 4$ & 26.1 & 302 & 216 \\
X3 & $100 \times \times 100 \times \times 5$ & $100 \times \times 100 \times \times 5$ & 20.5 & 373 & 325 \\
X4 & $100 \times 100 \times 6$ & $100 \times 100 \times 6$ & 17.2 & 560 & 393 \\
X5 & $100 \times 100 \times 8$ & $100 \times 100 \times 8$ & 12.6 & 783 & 565 \\
X6 & $250 \times 150 \times 5$ & $150 \times 150 \times 5$ & 50 & 409 & 260 \\
X7 & $150 \times 150 \times 6$ & $150 \times 150 \times 6$ & 25.6 & 828 & 628 \\
X8 & $350 \times 250 \times 10$ & $250 \times 250 \times 10$ & 35.3 & - & 1,270 \\
X9 & $400 \times 300 \times 8$ & $300 \times 300 \times 8$ & 50.5 & 1,289 & 670 \\
\hline
\end{tabular}

areas were then etched with an acid solution consisting of $10 \%$ nitric acid and $90 \%$ water. As an example, Fig. 10 shows the results for X3 and X5. Inspection of the welds revealed that full penetration was achieved in the joints with a chord thickness up to (and including) $5 \mathrm{~mm}$ (X1-X3), where the weld was very well fused with the parent material over the full wall thickness. However for the thickest specimens, X4 and X5, with wall thicknesses of 6 and $8 \mathrm{~mm}$, respectively, full penetration turned out to be difficult to achieve. The weld was incompletely fused at the root with a small gap being clearly visible. This conclusion is
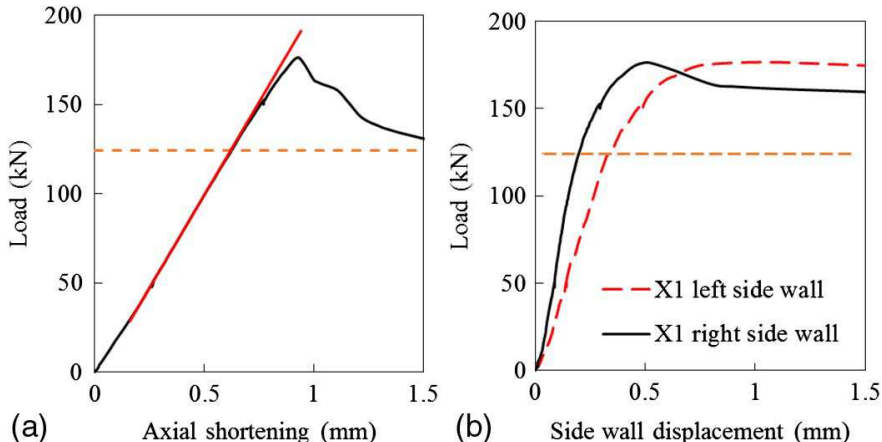

Fig. 8. Determination of buckling load $P_{b \text {,test }}$ for X1: (a) load versus axial shortening; (b) load versus sidewall displacement consistent with previous findings (Becque and Wilkinson 2011; Wardenier et al. 2009).

\section{Additional Test Data}

The limited database of five tests X1-X5 was augmented with another four experiments reported by Becque and Wilkinson (2011) 


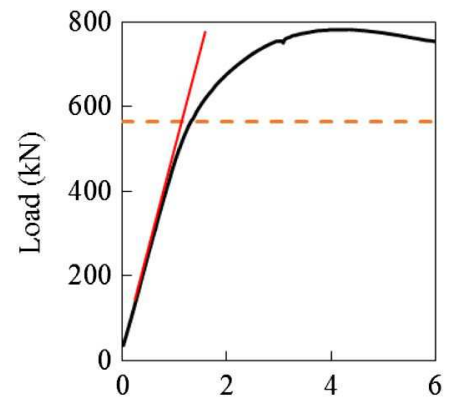

(a) Axial shortening (mm)

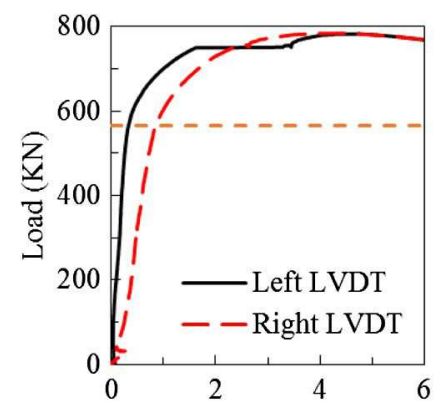

(b) Side wall displacement $(\mathrm{mm})$

F9:1

F9:2

Fig. 9. Determination of buckling load $P_{b \text {,test }}$ for X5: (a) load versus axial shortening; (b) load versus sidewall displacement

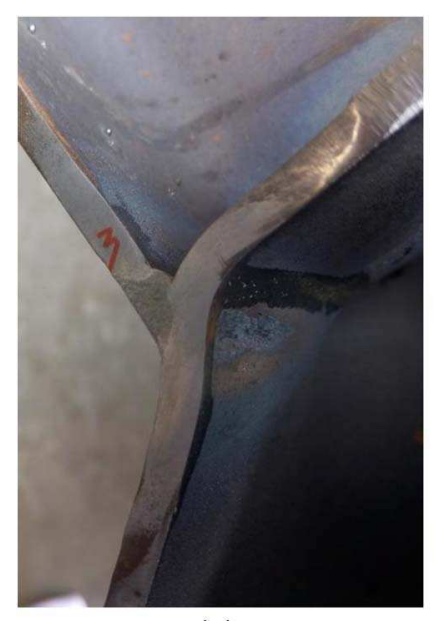

(a)

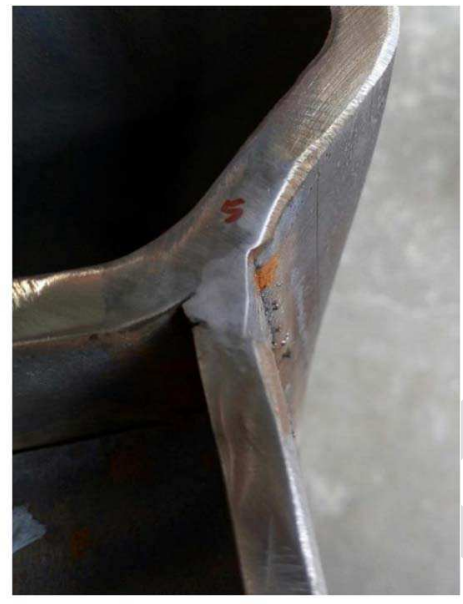

(b)

Fig. 10. Macro etching of welds: (a) X3; (b) X5

on equal-width $\mathrm{X}$-joints. The additional data pertain to connections made of grade $\mathrm{C} 450$ cold-formed tube and include rectangular as well as square chord members. The tests, which will be labeled $\mathrm{X} 6-\mathrm{X} 9$ in this paper, generally exhibit larger $h_{0} / t_{0}$ ratios (some even outside the range of applicability of the current CIDECT rules) and include much larger section sizes (up to RHS $400 \times$ $300 \times 8)$ than those included in X1-X5. Consequently, the resulting database $\mathrm{X} 1-\mathrm{X} 9$ contains a more balanced mix of geometries and material properties. The measured dimensions, as well as the material properties of $\mathrm{X} 6-\mathrm{X} 9$, are listed in Table 1, while the test results are listed in Table 2.

\section{Finite-Element Modeling}

A finite-element (FE) model was developed using ABAQUS and benchmarked against the nine experiments $\mathrm{X} 1-\mathrm{X} 9$ in Tables 1 and 2 (Becque and Wilkinson 2011, 2015).

The model was based on the measured dimensions, geometric imperfections, and weld sizes, which can be found in Table 1 and in (Becque et al. 2011; Guo 2014). Material properties obtained from the coupon test results were included in the model. For the weld material, an elastic-perfect plastic stress-strain relationship was used, based on the nominal material properties $\left(f_{y}=460 \mathrm{MPa}\right.$, $f_{u}=600 \mathrm{MPa}$ ), as shown in Fig. 11. Fig. 11 also shows the

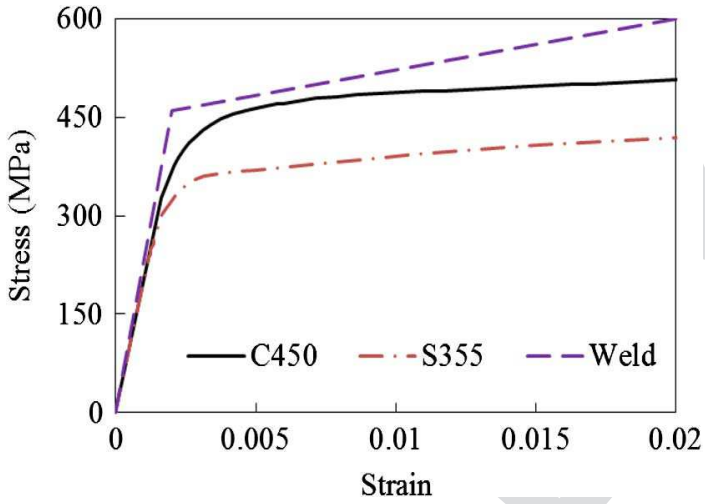

Fig. 11. Stress-strain curves

F11:1

stress-strain curves of S355 used to model X1-X5 and C450, used for X6-X9.

Boundary conditions consistent with the experiment were applied to the FE models. This meant that the brace ends were fixed (prevented from lateral displacement and overall rotation), while an axial displacement was imposed at one end with the other end kept in place. Specimens X6 and X7, which were tested between hinged boundary conditions (Becque and Wilkinson 2011), formed the exceptions. In those cases, rigid body constraints were used to tie all nodes in the brace end sections to the centroid of the cross section and rotations of the centroid about both axes of the cross section were allowed. Symmetry boundary conditions were applied whenever possible with only $1 / 8$ of the connection modeled.

Tie constraints were used to fuse the surfaces between the welds and the brace and chord members together. The surfaces of weld were thereby used as the master surfaces.

Three elements were used in the through-thickness direction of the RHS. Hexahedral elements were used throughout the model, except for the welds where tetrahedral elements were employed because of the complexity of the geometry. A global mesh size of twice the thickness of chord was used, while a finer mesh size of about $2 / 3$ of the chord sidewall thickness was chosen for the region of the chord sidewall under the brace members, where sidewall buckling was expected to occur (Fig. 12).

The influences of the mesh size; the element type (i.e., linear versus quadratic elements); and the analysis solver were investigated in a sensitivity study using test X7. A total of 10 models were run, covering mesh sizes ranging from 2 to $15 \mathrm{~mm}$ (in the most refined region), 8-node as well as 20-node hexahedral elements, and general static versus Riks analyses. The peak load $P_{\text {ult }}$, the axial shortening $d$ at the peak load $P_{\text {ult }}$, and the initial stiffness $K_{i}$ obtained from the models are compared in Table 3 and Fig. 13. It was found that the results are quite insensitive to both the mesh size and the number of nodes in the element, as long as the mesh size is smaller than the chord wall thickness in the most refined region. However, a 20-node quadratic hexahedral element significantly increased the running time and was therefore not used in the analysis. Quadratic tetrahedral elements were adopted in the welds in all cases, nevertheless, because of the occasionally high aspect ratios of the elements. No noticeable difference in results was obtained between a Riks or a general static analysis and Riks analyses were used because of their computational efficiency.

The FE results for all nine tests $\mathrm{X} 1-\mathrm{X} 9$ are compared to the experimental data in Table 4 with respect to the peak load $P_{\text {ult }}$, the initial axial stiffness $K_{i}$, and the axial shortening $d$ at the peak load. Good agreement was generally achieved between the FE models and the test data. The average ratio of the FE predicted load 


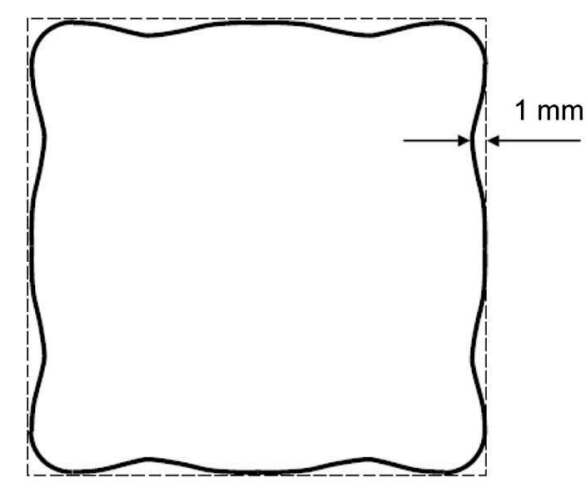

(a)

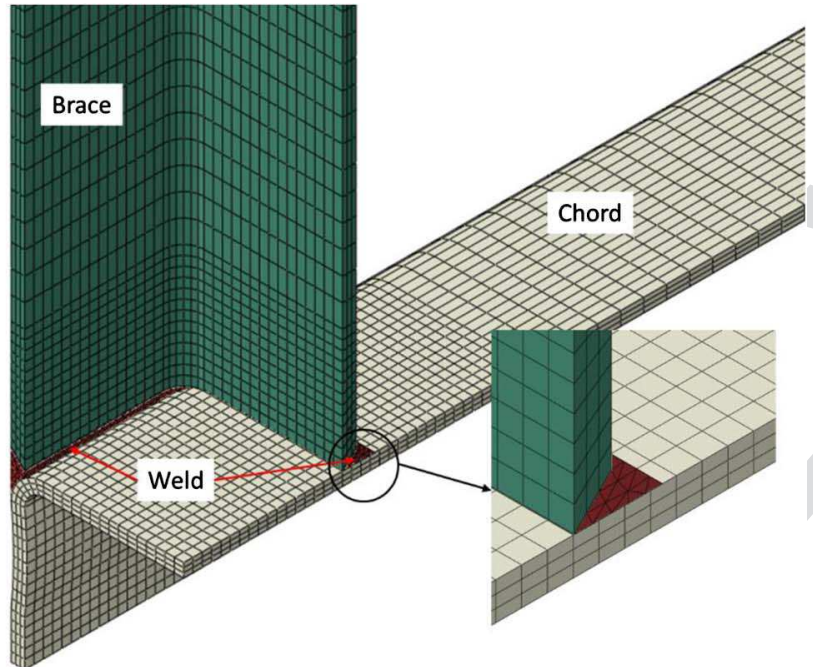

(b)

Fig. 12. Finite-element model of X7: (a) measured chord imperfections; (b) finite-element mesh

Table 3. Sensitivity Studies

\begin{tabular}{lcccccc}
\hline Label & $\begin{array}{c}\text { Element } \\
\text { type }\end{array}$ & $\begin{array}{c}\text { Analysis } \\
\text { solver }\end{array}$ & $\begin{array}{c}\text { Mesh } \\
\text { size }(\mathrm{mm})\end{array}$ & $\begin{array}{c}P_{\text {ult }} \\
(\mathrm{kN})\end{array}$ & $\begin{array}{c}d \\
(\mathrm{~mm})\end{array}$ & $\begin{array}{c}K_{i} \\
(\mathrm{kN} / \mathrm{mm})\end{array}$ \\
\hline Test & - & - & - & 832.35 & 2.68 & 353 \\
S1 & Hex-8 & Riks & 2 & 860.42 & 3.03 & 356 \\
S2 & Hex-8 & Riks & 3 & 860.42 & 3.05 & 356 \\
S3 & Hex-8 & Riks & 4 & 859.9 & 3.05 & 355 \\
S4 & Hex-20 & Riks & 4 & 888.62 & 3.15 & 356 \\
S5 & Hex-8 & Static & 4 & 859.3 & 3.02 & 353 \\
S6 & Hex-8 & Riks & 5 & 858.8 & 3.02 & 355 \\
S7 & Hex-8 & Riks & 6 & 865.82 & 3.07 & 354 \\
S8 & Hex-8 & Riks & 8 & 888.62 & 3.15 & 353 \\
S9 & Hex-8 & Riks & 10 & 826.89 & 3.22 & 347 \\
S10 & Hex-8 & Riks & 15 & 998.11 & 4.62 & 351 \\
\hline
\end{tabular}

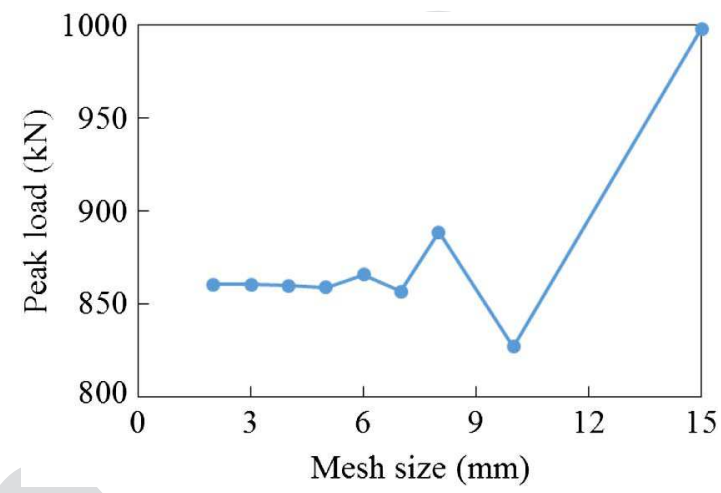

F13:1 Fig. 13. Effect of mesh size (Hex-8 elements and Riks analysis) to the measured ultimate capacity $\left(P_{\text {ult,FEA }} / P_{\text {ult,test }}\right)$ was found to be 1.03 with a standard deviation of 0.09 . A comparison of the peak load for X8 was not included because the peak load was not reached in the test. To further illustrate the predictive capacity of the FE models, Fig. 14 compares the predicted and the measured load versus axial shortening behavior and load versus sidewall deflection behavior of specimen X1.
Table 4. FE Model Validation

\begin{tabular}{|c|c|c|c|c|c|}
\hline $\begin{array}{l}\text { Perspectives of } \\
\text { comparison }\end{array}$ & Label & Test & FEA & FEA/test & $\mathrm{T} 4: 1$ \\
\hline \multirow{11}{*}{$\begin{array}{l}\text { Ultimate load, } \\
P_{\text {ult }}(\mathrm{kN})\end{array}$} & $\mathrm{X} 1$ & 176 & 182 & 1.03 & $\mathrm{~T} 4: 2$ \\
\hline & $\mathrm{X} 2$ & 302 & 270 & 0.89 & $\mathrm{~T} 4: 3$ \\
\hline & X3 & 373 & 434 & 1.16 & $\mathrm{~T} 4: 4$ \\
\hline & $\mathrm{X} 4$ & 560 & 501 & 0.89 & $\mathrm{~T} 4: 5$ \\
\hline & X5 & 783 & 789 & 1.01 & T4:6 \\
\hline & X6 & 409 & 448 & 1.10 & T4:7 \\
\hline & $X 7$ & 828 & 862 & 1.04 & $\mathrm{~T} 4: 8$ \\
\hline & $\mathrm{X} 8$ & - & 2,045 & - & T4:9 \\
\hline & X9 & 1,289 & 1,405 & 1.09 & $\mathrm{~T} 4: 10$ \\
\hline & - & - & Average & 1.03 & $\mathrm{~T} 4: 11$ \\
\hline & - & - & SD & 0.10 & $\mathrm{~T} 4: 12$ \\
\hline \multirow{11}{*}{$\begin{array}{l}\text { Initial stiffness, } \\
K_{i}(\mathrm{kN} / \mathrm{mm})\end{array}$} & $\mathrm{X} 1$ & 208 & 233 & 1.12 & $\mathrm{~T} 4: 13$ \\
\hline & $\mathrm{X} 2$ & 229 & 312 & 1.36 & $\mathrm{~T} 4: 14$ \\
\hline & X3 & 291 & 392 & 1.35 & T4:15 \\
\hline & $\mathrm{X} 4$ & 369 & 458 & 1.24 & T4:16 \\
\hline & X5 & 459 & 624 & 1.36 & $\mathrm{~T} 4: 17$ \\
\hline & X6 & 271 & 252 & 0.93 & T4:18 \\
\hline & $X 7$ & 411 & 373 & 0.91 & T4:19 \\
\hline & X8 & 810 & 737 & 0.91 & $\mathrm{~T} 4: 20$ \\
\hline & X9 & 870 & 698 & 0.80 & $\mathrm{~T} 4: 21$ \\
\hline & - & - & Average & 1.11 & $\mathrm{~T} 4: 22$ \\
\hline & - & - & SD & 0.23 & $\mathrm{~T} 4: 23$ \\
\hline \multirow{11}{*}{$\begin{array}{l}\text { Axial shortening, } \\
d(\mathrm{~mm})\end{array}$} & $\mathrm{X} 1$ & 0.92 & 0.9 & 0.98 & T4:24 \\
\hline & $\mathrm{X} 2$ & 1.6 & 1.03 & 0.64 & $\mathrm{~T} 4: 25$ \\
\hline & $\mathrm{X} 3$ & 1.75 & 1.68 & 0.96 & $\mathrm{~T} 4: 26$ \\
\hline & $\mathrm{X} 4$ & 2.46 & 1.69 & 0.69 & $\mathrm{~T} 4: 27$ \\
\hline & X5 & 4.03 & 3.87 & 0.96 & $\mathrm{~T} 4: 28$ \\
\hline & X6 & 5.07 & 2.55 & 0.50 & T4:29 \\
\hline & $X 7$ & 2.65 & 3.02 & 1.14 & $\mathrm{~T} 4: 30$ \\
\hline & $\mathrm{X} 8$ & - & 3.64 & - & $\mathrm{T} 4: 31$ \\
\hline & X9 & 2.22 & 3.54 & 1.59 & $\mathrm{~T} 4: 32$ \\
\hline & - & - & Average & 0.93 & $\mathrm{~T} 4: 33$ \\
\hline & - & - & $\mathrm{SD}$ & 0.34 & $\mathrm{~T} 4: 34$ \\
\hline
\end{tabular}

The FE models were subsequently used to accurately determine the loads at which sidewall buckling occurs, particularly for those connections where sidewall buckling occurs in the inelastic range and the buckling load is difficult to identify from the experimental
346 347

348 349 

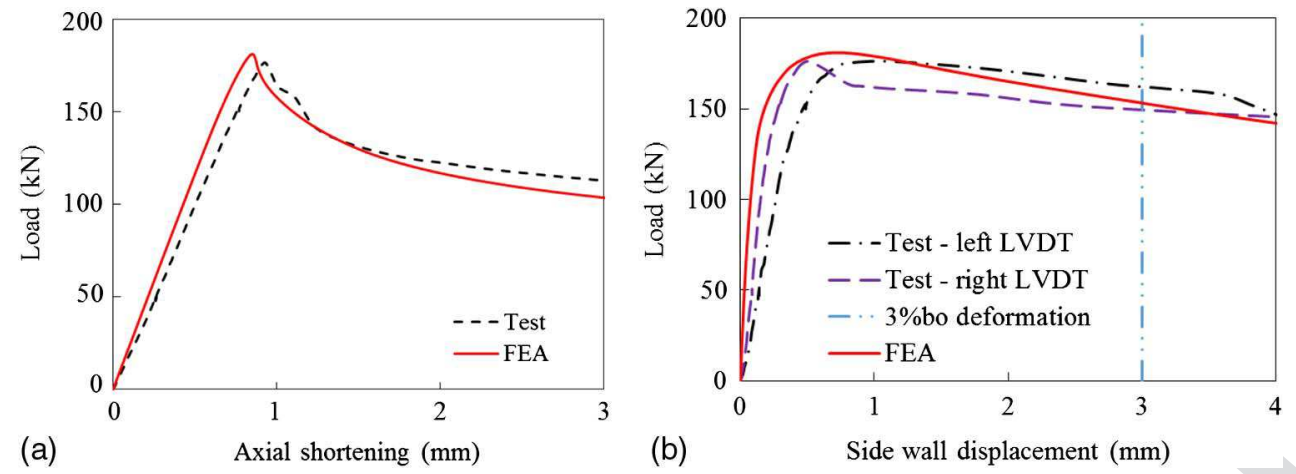

Fig. 14. Comparison of test and FEA (X1): (a) load-axial shortening curve; (b) load-sidewall deflection curve
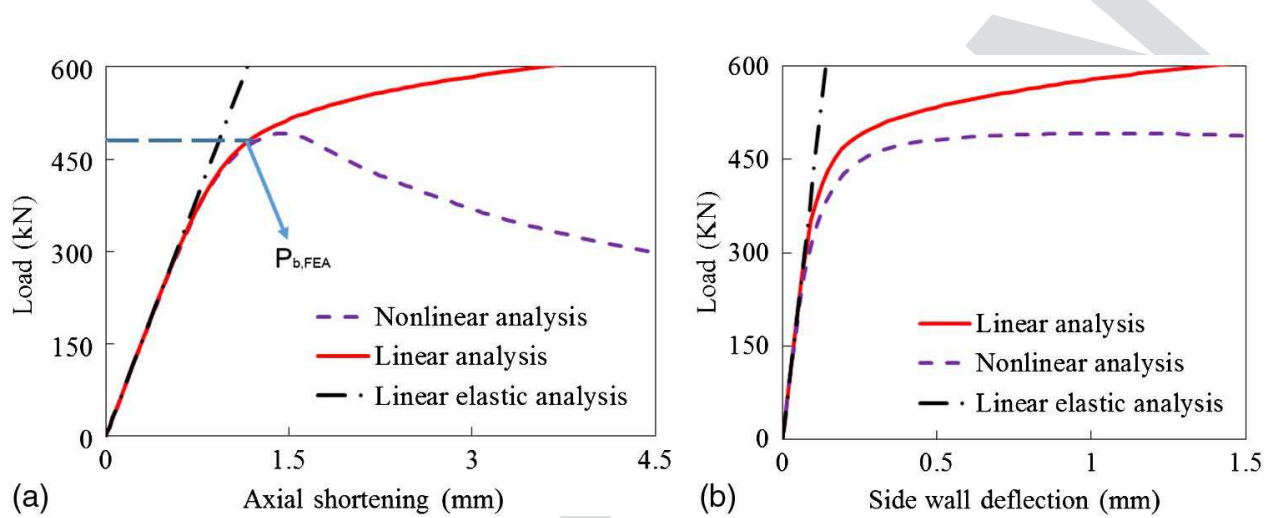

Fig. 15. Comparison of buckling loads: (a) axial load versus axial shortening; (b) axial load versus sidewall deflection

data. The buckling load was thereby determined from the divergence point between a geometric nonlinear analysis and a linear analysis (both including material nonlinearity) in the load versus axial shortening diagram [Fig. 15(a)].

A comparison of the experimental and FE-determined buckling loads is plotted in Fig. 16. The figure shows that, generally, a very good agreement is obtained for specimens buckling in the elastic range, in which case buckling was determined experimentally by observing the change in axial stiffness. For those specimens buckling in the inelastic range, however, it appears that determining the buckling point experimentally from the increase in sidewall

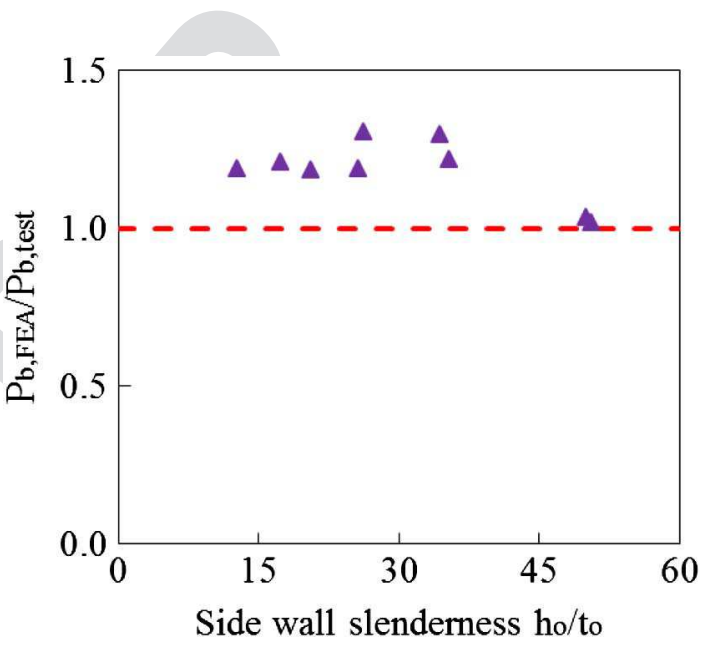

F16:1

Fig. 16. Comparison of buckling loads displacements leads to slightly conservative estimates, and that some softening of the load versus sidewall displacements curve as a result of gradual yielding typically precedes the actual point of buckling.

\section{Theoretical Model}

In a next step, a representative theoretical model was developed by representing the chord sidewall by a plate with thickness $t_{0}$, which extends to infinity on both sides (Fig. 17). The plate was thereby assumed to be made of a linear elastic and homogeneous material. The loads and boundary conditions were idealized as follows:

1. It was assumed that the distributed load $p$ transferred from the brace sidewall into the chord sidewall is uniformly over the

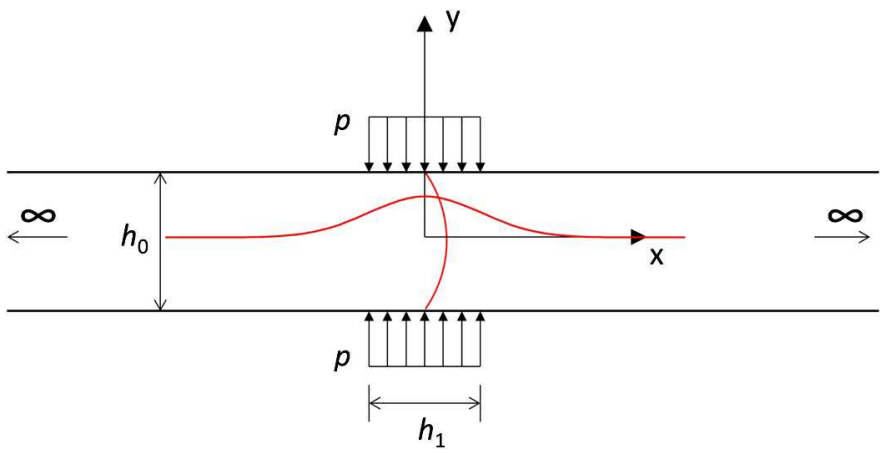

Fig. 17. Idealized model 
brace width $h_{1}$. The total load $P$ carried by the connection (comprising two sidewalls) is then given by

$$
P=2 p h_{1}=2 \sigma t_{0} h_{1}
$$

where the stress $\sigma=p / t_{0}$.

2. The plate is hinged along the longitudinal edges. This is obviously a conservative assumption, neglecting any restraint provided by the chord top and bottom faces and by the welded connection to the brace member.

A Rayleigh-Ritz approach was used by substituting a function representative of the deformed shape into the energy potential. The traditional, most straightforward approach would thereby be to use a multiplicative solution consisting of a half-sine wave function over the depth of the chord and a (truncated) Fourier series in the longitudinal direction

$$
w=\Delta \cos \left(\frac{\pi y}{h_{0}}\right) \sum_{i=1}^{N} \cos \left(i \frac{\pi x}{L}\right) x \in\left[-\frac{L}{2}, \frac{L}{2}\right]
$$

where $w=$ out-of-plane displacement of the plate; $\Delta=$ amplitude of the displacement; $N=$ integer determining the number of Fourier terms to be included; and $L$ determines a sufficiently large interval is that a large number of Fourier terms would be needed to accurately describe the buckle. Indeed, the more localized a function is in space, the wider the frequency spectrum of its Fourier transform. For instance, in the limit case, the Dirac delta function (consisting tion, meaning that all frequencies from $-\infty$ to $+\infty$, with equal weight, are needed to describe it though a Fourier series. This approach would also preempt a closed-form solution.

Therefore, the exponential Gauss function is instead chosen to represent the longitudinal shape of the buckle. This function is an ideal candidate to capture the localized nature of the failure mode, since its ordinates approach zero almost immediately when leaving a localized area around the origin. When also adopting a half-sine wave solution in the transverse direction (across the depth of the chord wall), the proposed deformed shape is expressed by the following function:

$$
w=\Delta \cos \left(\frac{\pi y}{h_{0}}\right) e^{-2 B x^{2}}
$$

In the above equation, $w$ is again the out-of-plane displacement eters. $\Delta$ determines the amplitude of the displacements, while $B$ is related to the length of the buckle. The Gauss function is prominently featured in statistics and from the study of the Gaussian (normal) distribution it is known that only $0.27 \%$ of the points in the distribution are more than three standard deviations removed from the average. From a comparison between Eq. (3) and the standard expression of the Gaussian distribution

$$
f(x, \mu, s)=\frac{1}{s \sqrt{2 \pi}} e^{-\frac{(x-\mu)^{2}}{2 s^{2}}}
$$

where $\mu=$ average and $s=$ standard deviation, an approximate length of the buckle can be determined as

$$
L_{b}=6 \mathrm{~s}=\frac{3}{\sqrt{B}}
$$

The elastic strain energy $U$ contained in the deformed shape of the plate is given by [e.g., (Timoshenko and Gere 1961)] centered on the connection. However, the drawback of this method of a single value peak) Fourier transforms into the constant funcof the plate, while $\Delta$ and $B$ are (presently undetermined) param-

$$
\begin{aligned}
U= & \frac{D}{2} \int_{x=-\infty}^{x=\infty} \int_{y=-h_{0} / 2}^{y=h_{0} / 2}\left\{\left(\frac{\partial^{2} w}{\partial x^{2}}\right)^{2}+\left(\frac{\partial^{2} w}{\partial y^{2}}\right)^{2}+2 \nu\left(\frac{\partial^{2} w}{\partial x^{2}}\right)\left(\frac{\partial^{2} w}{\partial y^{2}}\right)\right. \\
& \left.+2(1-\nu)\left(\frac{\partial^{2} w}{\partial x \partial y}\right)^{2}\right\} d x d y
\end{aligned}
$$

In the above equation, $D$ is the flexural rigidity of the plate, given by

$$
D=\frac{E t_{0}^{3}}{12\left(1-\nu^{2}\right)}
$$

where $E=$ modulus of elasticity and $\nu=$ Poisson's ratio. Substitution of Eq. (3) into Eq. (6) requires computation of the following integrals:

$$
\begin{aligned}
& \int_{-\infty}^{\infty} x^{2} e^{-4 B x^{2}} d x=\frac{1}{16 B} \sqrt{\frac{\pi}{B}} \\
& \int_{-\infty}^{\infty} x^{4} e^{-4 B x^{2}} d x=\frac{3}{128 B^{2}} \sqrt{\frac{\pi}{B}}
\end{aligned}
$$

and eventually leads to

$$
U=\frac{\Delta^{2} D}{2} \sqrt{\frac{\pi}{B}}\left(3 B^{2} h_{0}+B \frac{\pi^{2}}{h_{0}}+\frac{\pi^{4}}{4 h_{0}^{3}}\right)
$$

On the other hand, the potential energy of the applied stresses is given by

$$
V=-\frac{\sigma t_{0}}{2} \int_{x=-h_{1} / 2}^{x=h_{1} / 2} \int_{y=-h_{0} / 2}^{y=h_{0} / 2}\left(\frac{\partial w}{\partial y}\right)^{2} d x d y
$$

or, after substituting Eq. (3) into Eq. (11),

$$
V=-\frac{\Delta^{2} \sigma t_{0} \pi^{2}}{4 h_{0}} \int_{x=-h_{1} / 2}^{x=h_{1} / 2} e^{-4 B x^{2}} d x
$$

The remaining integral in Eq. (12) does not have a closed-form solution and can only be expressed as a series

$$
V=-\frac{\Delta^{2} \sigma t_{0} \pi^{2}}{4 h_{0}}\left[h_{1}-\frac{h_{1}^{3} B}{3}+\ldots\right]
$$

Only the first term in the series is retained, so that

$$
V=-\frac{\Delta^{2} \sigma t_{0} \pi^{2}}{2}\left(\frac{h_{1}}{h_{0}}\right)
$$

Neglecting the higher order terms is acceptable, provided that

$$
\frac{h_{1}^{3} B}{3} \ll h_{1} \quad \text { or } \quad \frac{h_{1}^{2} B}{3} \ll 1
$$

It will be shown at a later stage (once an expression for $B$ has been determined) that this is indeed a reasonable assumption.

The derivatives of the total energy $U+V$ with respect to $B$ and $\Delta$ are set equal to zero 


$$
\begin{aligned}
& \frac{\partial(U+V)}{\partial B}=0 \\
& \frac{\partial(U+V)}{\partial \Delta}=0
\end{aligned}
$$

The calculations eventually result in simple equations

$$
B=\left(\frac{\sqrt{10}-1}{18}\right)\left(\frac{\pi}{h_{0}}\right)^{2}=\frac{1.186}{h_{0}^{2}}
$$

436

and

$$
\sigma_{c r}=1.346 \frac{\pi^{2} E}{12\left(1-\nu^{2}\right)} \frac{t_{0}^{2}}{h_{0} h_{1}}
$$

For $E=210 \mathrm{GPa}$ and $\nu=0.3$, Eq. (19) becomes

$$
\sigma_{c r}=\left(255 \times 10^{3}\right) \frac{t_{0}^{2}}{h_{0} h_{1}}(\mathrm{MPa})
$$

The critical buckling load of the connection is then given by

$$
P_{c r}=2 t_{0} h_{1} \sigma_{c r}=511 \frac{t_{0}^{3}}{h_{0}}(\mathrm{kN})
$$

The condition in Eq. (15) can now be evaluated by substituting Eq. (18) into Eq. (15), which yields

$$
\left(\frac{h_{1}}{h_{0}}\right)^{2} \ll 2.53
$$

\section{Proposed Design Method}

Table 5 summarizes, for each specimen, the elastic critical buckling load $P_{c r}$ obtained using Eq. (21), the experimental and numerical buckling loads $P_{b \text {,est }}$ and $P_{b \text {,FEA }}$, and the yield load $P_{y}$, which is taken as

$$
P_{y}=1.2 \times 2 f_{y} h_{1} t_{0}=2.4 f_{y} h_{1} t_{0}
$$

The factor 1.2 thereby takes into account that a small part of the load follows an alternative load path through the chord top and bottom faces, followed by it spreading out into the chord sidewalls. This factor agrees well with the ultimate load observed in the stockiest joint (X5) and appears to be on the conservative side based on experimental results and equations provided in (Davies and Packer 1987; Packer 1984).

Based on Eqs. (21) and (25), a nondimensional slenderness can be defined as

$$
\lambda=\sqrt{\frac{P_{y}}{P_{c r}}}=\frac{\sqrt{f_{y} h_{0} h_{1}}}{500 t_{0}}
$$

In Fig. 18 the nondimensional buckling loads $P_{b, \mathrm{FEA}} / P_{y}$ and $P_{b \text {,test }} / P_{y}$ obtained from all FE models and tests, respectively, are plotted against the calculated slenderness values $\lambda$ (the elastic critical buckling load is also shown in the dashed line)

$$
\frac{P_{c r}}{P_{y}}=\frac{\sigma_{c r}}{f_{y}}=\frac{1}{\lambda^{2}}
$$

The figure shows that both buckling loads, $P_{b \text {,test }}$ and $P_{b, \text { FEA }}$, show good agreement with the elastic buckling curve in the slender range, where $P_{c r}$ is sufficiently below $P_{y}$. It confirms that the previously proposed model of an infinitely long plate under patch loading is able to capture the main parameters determining the sidewall behavior. Some conservative assumptions have been made in the model: the flat width of the sidewall has been slightly exaggerated by neglecting the rounded corners, and any restraint along the longitudinal edges exerted by the chord top and bottom faces and the brace members has been neglected, instead assuming hinged boundary conditions. However, a minor portion of the load does not enter the sidewall directly from the brace wall above (or below), but instead flows through the brace walls perpendicular to the sidewall and through the chord top and bottom faces, thus causing additional bending in the sidewall as a result of the load eccentricity. The model also assumes a perfectly flat plate, while the real chord wall inevitably contains imperfections. It seems that all these

\begin{tabular}{|c|c|c|c|c|c|c|c|c|c|c|c|}
\hline Test & $\begin{array}{c}h_{0} / t_{0} \\
(=2 \gamma)\end{array}$ & $\begin{array}{c}P_{b, \text { test }} \\
(\mathrm{kN})\end{array}$ & $\begin{array}{c}P_{b, \mathrm{FEA}} \\
(\mathrm{kN})\end{array}$ & $\begin{array}{c}P_{d, \mathrm{CIDECT}} \\
(\mathrm{kN})\end{array}$ & $\begin{array}{c}P_{\text {ult,CIDECT }} \\
(\mathrm{kN})\end{array}$ & $P_{\mathrm{ult}, \mathrm{CIDECT}} / P_{b, \mathrm{FEA}}$ & $\begin{array}{c}P_{c r} \\
(\mathrm{kN})\end{array}$ & $\begin{array}{c}P_{y} \\
(\mathrm{kN})\end{array}$ & $\lambda$ & $\begin{array}{l}P_{\text {pred }} \\
(\mathrm{kN})\end{array}$ & $P_{\text {pred }} / P_{b, \text { FEA }}$ \\
\hline$\overline{X 1}$ & 34.3 & 124 & 162 & 61 & 76 & 0.45 & 125 & 232 & 1.36 & 114 & 0.70 \\
\hline $\mathrm{X} 2$ & 26.1 & 216 & 282 & 122 & 153 & 0.55 & 285 & 305 & 1.03 & 228 & 0.81 \\
\hline $\mathrm{X} 3$ & 20.5 & 325 & 386 & 236 & 295 & 0.80 & 594 & 469 & 0.89 & 401 & 1.04 \\
\hline $\mathrm{X} 4$ & 17.2 & 393 & 477 & 319 & 399 & 0.84 & 995 & 513 & 0.72 & 475 & 1.00 \\
\hline X5 & 12.6 & 565 & 672 & 520 & 649 & 0.97 & 2,465 & 654 & 0.52 & 632 & 0.94 \\
\hline X6 & 50.0 & 260 & 270 & 75 & 104 & 0.39 & 243 & 834 & 1.85 & 231 & 0.86 \\
\hline$X 7$ & 25.6 & 628 & 748 & 285 & 396 & 0.50 & 652 & 953 & 1.21 & 573 & 0.77 \\
\hline $\mathrm{X} 8$ & 35.3 & 1,270 & 1,550 & 482 & 669 & 0.43 & 1,364 & 2,778 & 1.43 & 1,254 & 0.81 \\
\hline X9 & 50.5 & 670 & 682 & 227 & 315 & 0.46 & 604 & 2,745 & 2.13 & 579 & 0.85 \\
\hline - & - & - & - & \multicolumn{2}{|c|}{ Average } & 0.60 & - & - & \multicolumn{2}{|c|}{ Average } & 0.86 \\
\hline - & - & - & - & \multicolumn{2}{|c|}{ SD } & 0.21 & - & - & \multicolumn{2}{|c|}{ SD } & 0.10 \\
\hline - & - & - & - & \multicolumn{2}{|c|}{$\mathrm{COV}$} & 0.35 & - & - & \multicolumn{2}{|c|}{$\mathrm{COV}$} & 0.11 \\
\hline
\end{tabular}

Table 5. Test Results and Predicted Capacities 


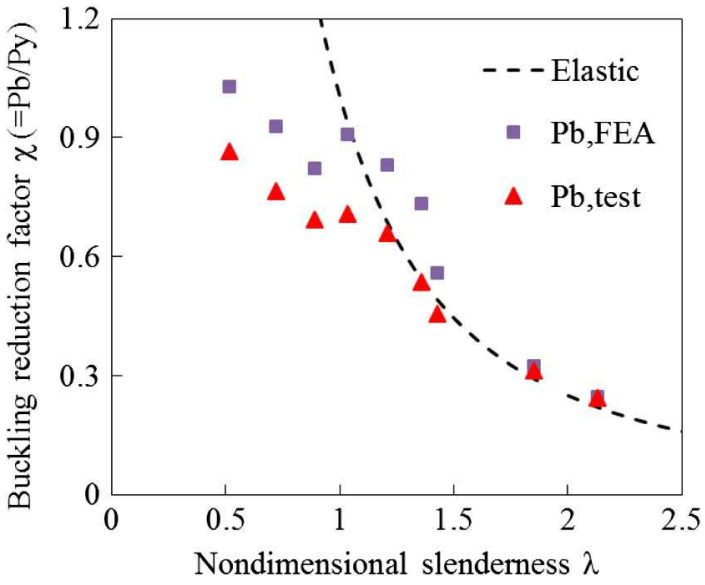

F18:1
Fig. 18. Comparison between test and elastic buckling curve

effects, beneficial or detrimental, largely oppose and balance each other, turning our simplified model into a perfectly usable model as the basis for design.

Fig. 18 shows that, not unexpectedly, the experimental and numerical data start to deviate from the elastic curve at lower slenderness values as a result of gradual yielding. In what follows, the FE determined buckling loads (rather than the test results) will be taken as a benchmark in the inelastic range, since they were obtained through an accurate rational procedure [Fig. 15(a)], rather than through visual inspection of the experimental load versus sidewall displacement curves.

To extend the design model into the inelastic range we draw on the work by Bleich (1952), who proposed the following differential equation to describe buckling of a simply supported inelastic plate under uniaxial compression:

$$
E_{t} \frac{\partial^{4} w}{\partial x^{4}}+2 \sqrt{E_{t} E} \frac{\partial^{4} w}{\partial x^{2} \partial y^{2}}+E \frac{\partial^{4} w}{\partial y^{4}}=-\sigma_{x} \frac{12\left(1-\nu^{2}\right)}{t_{0}^{2}} \frac{\partial^{2} w}{\partial x^{2}}
$$

In the above equation $E_{t}$ is the tangent modulus and $E$ is the elastic modulus. Although Bleich's equation is based on a semirational approach and more theoretically sound models have been developed (Becque 2010), it has the advantage of leading to rather simple equations. Indeed, the structure of Eq. (28) dictates that the inelastic buckling stress can be obtained from the corresponding buckling stress of an elastic plate by multiplying the latter with a plasticity reduction factor $\eta$, given by

$$
\eta=\sqrt{\frac{E_{t}}{E}}
$$

Using Eqs. (19) and (29), the following equation for the inelastic buckling stress of the chord sidewall is obtained:

$$
\sigma_{b}=1.346 \frac{\pi^{2} \sqrt{E E_{t}}}{12\left(1-\nu^{2}\right)} \frac{t_{0}^{2}}{h_{0} h_{1}}
$$

or, with $E=210 \mathrm{GPa}$ and $\nu=0.3$,

$$
\sigma_{b}=557 \sqrt{E_{t}} \frac{t_{0}^{2}}{h_{0} h_{1}}\left(E_{t} \text { in } \mathrm{MPa}\right)
$$

The tangent modulus $E_{t}$ can thereby be obtained from a Ramberg-Osgood representation of the material stress-strain curve

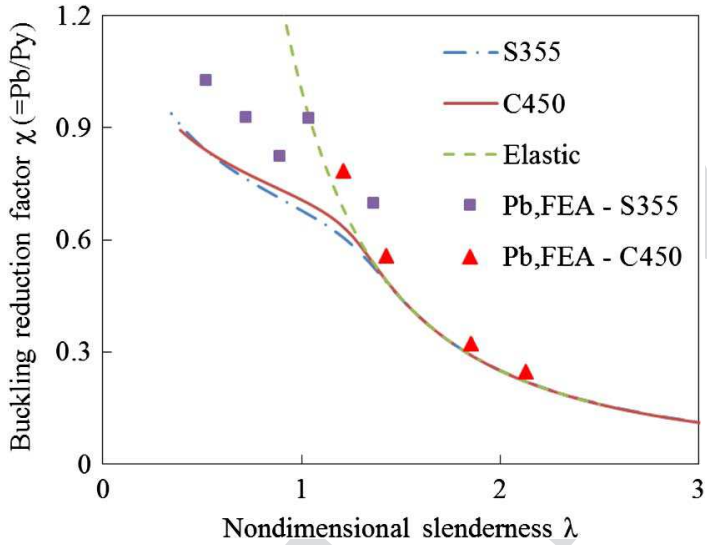

Fig. 19. Comparison between test and inelastic buckling model

F19:1

$$
E_{t}=\frac{f_{y} E}{f_{y}+0.002 n E\left(\frac{\sigma}{f_{y}}\right)^{n-1}}
$$

where $n$ is a parameter characterizing the roundness of the stressstrain curve. Using the measured values, $n=14, E=210 \mathrm{GPa}$, and $f_{y}=466 \mathrm{MPa}$ for the $\mathrm{S} 355$ material and $n=18, E=$ $210 \mathrm{GPa}$, and $f_{y}=466 \mathrm{MPa}$ for the $\mathrm{C} 450$ material. Eq. (31) can be plotted (Fig. 19) and compared to the numerical buckling loads $P_{b, \mathrm{FEA}}$.

Eq. (31) is simple in form, elegant, and considerably accurate, and it covers the whole slenderness range with one equation. However, it has the important drawback that it is iterative in nature. Indeed, the tangent modulus $E_{t}$ has to be calculated at the buckling stress $\sigma_{b}$. In order to eliminate this disadvantage, an alternative design equation is proposed, which more closely resembles the current CIDECT practice of referring to the equations for column buckling [e.g., EN1993-1-1 (CEN 2005)] in the design for sidewall buckling

$$
P_{b}=\chi P_{y}
$$

with

$$
\begin{gathered}
\chi=\frac{1}{\phi+\sqrt{\phi^{2}-\lambda^{2}}} \leq 1.0 \\
\phi=\frac{1}{2}\left[1+\alpha(\lambda-0.2)+\lambda^{2}\right]
\end{gathered}
$$

where $P_{y}$ and $\lambda$ are determined by Eqs. (25) and (26), respectively. The value of the imperfection factor $\alpha$ is taken as 0.08 , as it provides a conservative fit of the design curve to the data (Fig. 20).

Fig. 20 shows good agreement between Eqs. (33)-(35) and the buckling loads $P_{b \text {.FEA }}$. Table 5 lists the ratios of the capacity predicted by Eq. (33) to the numerical result $P_{b, \mathrm{FEA}}$. An average ratio of 0.86 was obtained with a standard deviation of 0.10 . In order to compare the performance of the proposed design equation with that of the current CIDECT rules, it should be noted first that the CIDECT equations provide factored design resistances; i.e., they already contain an implicit safety factor $\gamma_{M}=1.25$ for sidewall buckling (Packer et al. 2009; Wardenier 1982). This is accounted for by the factor of 0.8 in the CIDECT equation for the buckling stress $f_{k}$ (Packer et al. 2009). Also, the CIDECT rules impose an extra reduction factor of 0.9 on the capacity of $\mathrm{C} 450$ connections (applicable to X6-X9) (Packer et al. 2009). In order to allow an objective comparison, the CIDECT predicted design resistances 


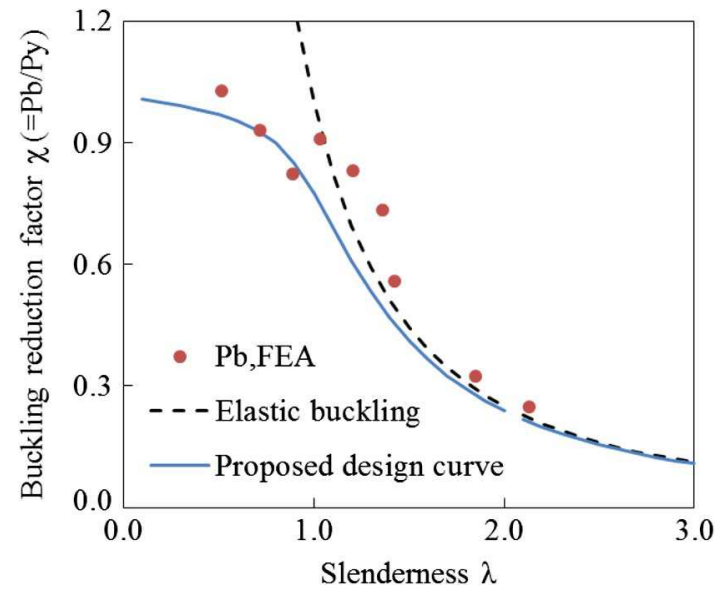

Fig. 20. Proposed design equation

$P_{d, \text { CIDECT }}$ in Table 5 were first transformed into nominal resistances $P_{\text {ult,CIDECT }}$ by dividing away the safety factor of 0.8 and, where applicable, the extra reduction factor of 0.9 . It can then be concluded that Eq. (33) strongly outperforms the current CIDECT design rule for sidewall buckling, which over the same data set features an average ratio of the predicted to the measured capacity of 0.6 with a standard deviation of 0.21 .

Importantly, Table 5 also shows that the CIDECT rule does not offer a consistent margin of safety. It is more conservative for sidewalls with high $h_{0} / t_{0}$ values. In this respect, the applicability of the current CIDECT rule is limited to an $h_{0} / t_{0}$ ratio of 40 . The new design rule proposed in Eqs. (33)-(35), however, has been verified against data including sections with $h_{0} / t_{0}$ ratios of up to 50 in Fig. 20 and Table 5.

\section{Reliability Analysis}

In order to ensure that the proposed design equations possess the required level of safety, a reliability analysis was performed within the framework of both the Eurocode (CEN 2002) and the AISI specifications (Hsiao et al. 1988). The target reliability index $\beta_{0}$ thereby needed to be taken as 3.8 according to Eurocode 0 (CEN 2002), and as 3.5 based on the AISI specifications (Hsiao et al. 1988), these being the values prescribed for connections. In the Eurocodes for structural steel, capacities are divided by a partial safety factor $\gamma_{M}$, while in the AISI specifications they are multiplied by a resistance factor $\Phi$.

In the Eurocode, the partial safety factor $\gamma_{M}$ is defined by

$$
\gamma_{M}=\frac{r_{n}}{r_{d}}
$$

where $r_{n}=$ nominal resistance determined by the proposed theoretical model and $r_{d}=$ design resistance. The method given in Annex D of Eurocode 0 (CEN 2002) was adopted to calculate the design resistance $r_{d}$

$$
r_{d}=b \cdot r_{m} \cdot e^{-\left[k_{d, \infty} \alpha_{r t} Q_{r t}+k_{d, n} \alpha_{\delta} Q \delta+0.5 Q^{2}\right]}
$$

in which $b=$ correction factor from model uncertainty and $r_{m}=$ resistance determined using the mean values of all relevant variables. Furthermore, $k_{d, \infty}=\alpha_{R} \beta_{0}=3.04$ is the target calibration level, where $\alpha_{R}=0.8$ is the sensitivity factor recommended by Eurocode 0 (CEN 2002). The factor $k_{d, n}$ is prescribed by the
Eurocode based on the number of tests $n$ available to verify the design equation against and, in this case, amounted to $k_{d, 9}=3.25$.

The correction factor $b$ is determined by the slope of the leastsquares regression line in the $P_{b, \mathrm{FEA}}$ versus $P_{\text {pred }}$ diagram

$$
b=\frac{\sum\left(P_{\text {pred }} \cdot P_{b, \text { FEA }}\right)}{\sum\left(P_{\text {pred }}\right)^{2}}=1.18
$$

An error term is also defined as

$$
\delta=\frac{P_{b, \mathrm{FEA}}}{P_{\text {pred }}}
$$

Let $Q_{r t}, Q_{\delta}$, and $Q$ denote the standard deviation of the resistance calculated using the design equation [Eq. (33)], the standard deviation of the error term $\delta$, and the overall standard deviation of the resistance, respectively. Assuming lognormal distributions, these standard deviations are obtained as

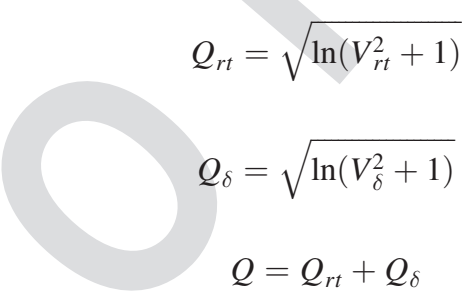

where $V_{r t}$ and $V_{\delta}=$ coefficients of variation (COVs) of the calculated resistance and the error term $\delta$, respectively. $V_{\delta}$ can be calculated using the values of $\delta$ obtained through Eq. (39). $V_{\delta}=0.125$ was thus obtained for the available data set and, subsequently, through Eq. (41), $Q_{\delta}=0.125$. However, determining $V_{r t}$ is not straightforward since the form of the resistance formula proposed in this paper is rather complex. The Eurocode (CEN 2002) recommends using a Taylor series approximation and retaining the first term in each basic variable $X_{i} . V_{r t}$ is then determined by

$$
\begin{aligned}
V_{r t}^{2}= & \frac{1}{r_{m}^{2}}\left(\sum_{i=1}^{j} \frac{\partial r}{\partial X_{i}} \sigma_{i}\right)^{2} \\
= & \frac{1}{r_{m}^{2}}\left[\left(\frac{\partial P_{b}}{\partial h_{0}} \sigma_{h o}\right)^{2}+\left(\frac{\partial P_{b}}{\partial h_{1}} \sigma_{h 1}\right)^{2}+\left(\frac{\partial P_{b}}{\partial t} \sigma_{t}\right)^{2}\right. \\
& \left.+\left(\frac{\partial P_{b}}{\partial E} \sigma_{E}\right)^{2}+\left(\frac{\partial P_{b}}{\partial f_{y}} \sigma_{f y}\right)^{2}\right]
\end{aligned}
$$

where $\sigma_{i}$ indicates the standard deviation of the basic variable $X_{i}$. The numerical values of $\sigma_{i}$ were obtained from (Packer et al. 2009) and are shown in Table 6. The partial derivatives in Eq. (43) were explicitly calculated using Eqs. (33)-(35).

The variables $\alpha_{r t}$ and $\alpha_{\delta}$ in Eq. (37) are weighting factors for $Q_{r t}$ and $Q_{\delta}$ respectively, calculated as

$$
\begin{gathered}
\alpha_{r t}=Q_{r t} / Q \\
\alpha_{\delta}=Q_{\delta} / Q
\end{gathered}
$$

The reliability calculations are presented in Table 7, where the partial safety factors $\gamma_{M}$ for all nine specimens X1-X9 are determined. They are seen to range between 1.30 and 1.69 , with an average value of 1.45. In order to achieve safe designs, a safety factor of 1.69 at the high end of the range was chosen. Thus, the proposed design equation within the framework of the Eurocode (CEN 2002) becomes

$$
P_{b, d}=0.6 \chi P_{y}
$$


Table 6. Statistical Distributions Used in Reliability Analysis

\begin{tabular}{|c|c|c|c|c|c|c|c|c|c|c|}
\hline T6:1 & \multicolumn{2}{|c|}{ Variable } & \multicolumn{3}{|c|}{ Distribution } & \multicolumn{4}{|c|}{ Nominal } & $\mathrm{M}$ \\
\hline T6:2 & $h_{0}$ & & \multicolumn{3}{|c|}{ Normal } & \multicolumn{4}{|c|}{$h_{0}$} & \\
\hline T6:3 & $h_{1}$ & & \multicolumn{3}{|c|}{ Normal } & \multicolumn{4}{|c|}{$h_{1}$} & \\
\hline T6:4 & $t$ & & \multicolumn{3}{|c|}{ Normal } & \multicolumn{4}{|c|}{$t$} & \\
\hline T6:5 & $E$ & & \multicolumn{3}{|c|}{ Normal } & \multicolumn{4}{|c|}{$E$} & \\
\hline T6:6 & $f_{y}$ & & \multicolumn{3}{|c|}{ Lognormal } & \multicolumn{4}{|c|}{$f_{y}$} & 1. \\
\hline T7:1 & Test & $\begin{array}{l}P_{\text {pred }} \\
(\mathrm{kN})\end{array}$ & $\begin{array}{c}P_{b, \text { FEA }} \\
(\mathrm{kN})\end{array}$ & $\begin{array}{c}r_{m} \\
(\mathrm{kN})\end{array}$ & $\begin{array}{c}r_{n} \\
(\mathrm{kN})\end{array}$ & $V_{r t}$ & $Q_{r t}$ & $Q$ & $\begin{array}{c}r_{d} \\
(\mathrm{kN})\end{array}$ & $\gamma_{M}$ \\
\hline$T 7: 2$ & $\mathrm{X} 1$ & 114 & 162 & 128 & 126 & 0.15 & 0.15 & 0.20 & 96 & 1.31 \\
\hline $\mathrm{T} 7: 3$ & $\mathrm{X} 2$ & 228 & 282 & 279 & 264 & 0.13 & 0.13 & 0.18 & 191 & 1.38 \\
\hline T7:4 & X3 & 401 & 386 & 442 & 392 & 0.10 & 0.10 & 0.16 & 253 & 1.55 \\
\hline $\mathrm{T} 7: 5$ & $\mathrm{X} 4$ & 475 & 477 & 575 & 497 & 0.09 & 0.09 & 0.16 & 347 & 1.43 \\
\hline T7:6 & X5 & 632 & 672 & 804 & 686 & 0.09 & 0.09 & 0.15 & 516 & 1.33 \\
\hline T7:7 & X6 & 231 & 270 & 244 & 242 & 0.16 & 0.16 & 0.20 & 149 & 1.63 \\
\hline & $X 7$ & 573 & 748 & 658 & 638 & 0.14 & 0.14 & 0.19 & 464 & 1.38 \\
\hline & $\mathrm{X} 8$ & 1,254 & 1,550 & 1,354 & 1,334 & 0.15 & 0.15 & 0.20 & 885 & 1.51 \\
\hline 11 & X9 & 579 & 682 & 628 & 625 & 0.16 & 0.16 & 0.20 & 386 & 1.62 \\
\hline
\end{tabular}

where $\chi$ and $P_{y}$ are calculated according to Eqs. (34) and (25), respectively.

A reliability analysis according to Eurocode 0 (CEN 2002) was also carried out for the sake of anyone preferring to use the iterative Eq. (31) in design. A maximum safety factor $\gamma_{M}$ of 1.55 and an average $\gamma_{M}$ of 1.23 were obtained.

According to the AISI specifications (Hsiao et al. 1988), the resistance factor $\Phi$ is defined as

$$
\phi=C_{\phi}\left(M_{m} F_{m} P_{m}\right) e^{-\beta_{0} \sqrt{V_{M}^{2}+V_{F}^{2}+C_{p} V_{P}^{2}+V_{Q}^{2}}}
$$

in which $C_{\Phi}=1.52$ for LRFD. Furthermore, $M_{m}=1.1$ and $F_{m}=$ 1.0 are the mean values of the material and fabrication factors, and $V_{M}=V_{F}=0.1$ are the corresponding CO versus $P_{m}=1.0$ is the mean value of the professional factor and $\beta_{0}=3.5$ is the target reliability index for connections in LRFD. $V_{P}$ is the COV of the ratios of the test results to the design predictions (equivalent to $V_{\delta}$ in the Eurocode) and $V_{Q}=0.21$ is the COV of the loads in LRFD. $C_{p}$ is a correction factor to account for the number of test samples $n$ and is given by

$$
C_{P}=\frac{n+1}{n} \frac{n-1}{n-3}
$$

By substituting all of these variables into Eq. (47), a resistance factor $\phi=0.65$ was obtained. Thus, the proposed design equation within the framework of the AISI specifications (Hsiao et al. 1988) becomes

$$
P_{b, d}=0.65 \chi P_{y}
$$

When following both the Eurocode and the AISI procedure, the safety factors turn out to be rather large. While this is mainly because of the stringent reliability factors $\beta_{0}$ (of 3.8 and 3.5 , respectively), the small sample size also plays a role. It is expected that the safety factors could be further reduced by extending the database of experimental and numerical results. This is planned as further research.

\section{Conclusions}

The paper presents a new design method to account for the sidewall failure of equal-width RHS X-joints. The approach is based on a rational analysis of an infinitely long elastic plate subject to a localized distributed load. A Rayleigh-Ritz approximation is used to obtain the critical elastic buckling stress, which is subsequently used in combination with the yield load of the connection in the definition of a slenderness parameter. The new design equation is compared to experimental results, which include X-joints made of SHS and RHS of widely varying sizes and wall slenderness values. The data also include the results of a limited test program carried out at the University of Sheffield and described in detail in the paper.

A good agreement between the proposed equation and the data is observed, with an average ratio of the predicted to the measured capacity of 0.86 and a standard deviation of 0.13 . A reliability analysis is also carried out, both within the framework of the Eurocode and the AISI specifications, and appropriate safety factors for design purposes are presented.

\section{References}

ABAQUS [Computer software]. Dassault Systèmes, Waltham, MA.

Becque, J. (2010). "Inelastic plate buckling." J. Eng. Mech., 10.1061/ (ASCE)EM.1943-7889.0000075, 1123-1130.

Becque, J., and Wilkinson, T. (2011). "Experimental investigation of the static capacity of grade C450 RHS T and X truss joints." 14th Tubular Structures, CRC Press.

Becque, J., and Wilkinson, T. (2015). "A new design equation for side wall buckling of RHS truss X-joints." 15th Tubular Structures, 1st Ed., CRC Press, 419-426.

Becque, J., Wilkinson, T., and Syam, A. (2011). Experimental investigation of $X$ and $T$ truss connections in C450 cold-formed rectangular hollow sections, University of Sydney, Sydney.

Bleich, F. (1952). Buckling strength of metal structures, McGraw-Hill, New York.

Brodka, J., and Szlendak, J. (1980). "Strength of cross joints in rectangular hollow sections." 26th Scientific Conf. of the Civil and Hydraulic Engineering Section of the Polish Academy of Science and of the Science Division of PZITB.

CEN. (2002). "Basis of structural design." Eurocode 0, European Committee for Standardization, Brussels.

CEN. (2005). "Design of steel structures-Part 1.1." Eurocode 3, European Committee for Standardization, Brussels.

CEN. (2006). "Hot finished structural hollow sections of non-alloy and fine grain steels. Technical delivery requirements." BS EN 10210-1, European Committee for Standardization, Brussels.

Davies, G., and Packer, J. (1987). "Analysis of web crippling in a rectangular hollow section." Proc. Inst. Civ. Eng., 83(4), 785-798.

Fang, M. (2004). "Theoretical and experimental research on uniplanar $\mathrm{X}$ - and multiplanar XX- joints made of square hollow sections." Ph.D. thesis, Xi' an Univ. of Architecture and Technology.

Guo, S. (2014). "Side wall buckling of RHS truss joints." M.Sc. thesis, Univ. of Sheffield.

Hemp, W. S. (1945). The theory of flat panels buckled in compression, Aeronautical Research Council, Reports and Memoranda. 


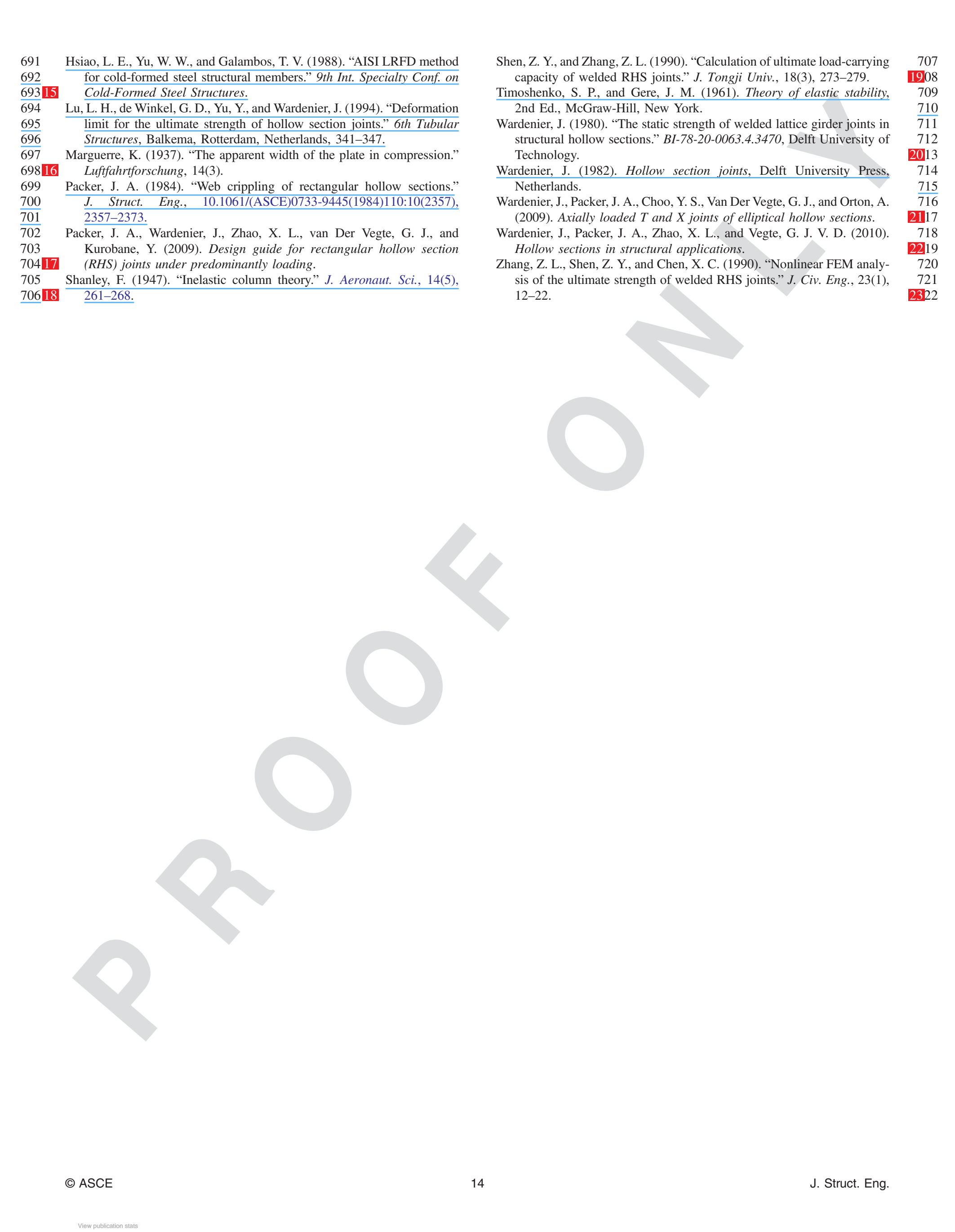

